\title{
Crustal complexity in the Lachlan Orogen revealed from teleseismic receiver functions
}

\section{F. R. FONTAINE ${ }^{1 *}$, H. TKALCIC ${ }^{2}$ AND B. L. N. KENNETT ${ }^{2}$}

'Laboratoire GéoSciences Réunion, Université de La Réunion, Institut de Physique du Globe de Paris, Sorbonne Paris Cité, UMR 7154 CNRS, Univ Paris Diderot, F-97715 Saint Denis, France.

${ }^{2}$ Research School of Earth Sciences, Australian National University, Canberra, ACT 0200, Australia.

\begin{abstract}
There is an ongoing debate about the tectonic evolution of southeast Australia, particularly about the causes and nature of its accretion to a much older Precambrian core to the west. Seismic imaging of the crust can provide useful clues to address this issue. Seismic tomography imaging is a powerful tool often employed to map elastic properties of the Earth's lithosphere, but in most cases does not constrain well the depth of discontinuities such as the Mohorovičić (Moho). In this study, an alternative imaging technique known as receiver function (RF) has been employed for seismic stations near Canberra in the Lachlan Orogen to investigate: (i) the shear-wave-velocity profile in the crust and uppermost mantle, (ii) variations in the Moho depth beneath the Lachlan Orogen, and (iii) the nature of the transition between the crust and mantle. A number of styles of RF analyses were conducted: $\mathrm{H}-\mathrm{K}$ stacking to obtain the best compressional-shear velocity $\left(V_{\mathrm{P}} / V_{\mathrm{S}}\right)$ ratio and crustal thickness; nonlinear inversion for the shear-wave-velocity structure and inversion of the observed variations in RFs with backazimuth to investigate potential dipping of the crustal layers and anisotropy. The thick crust (up to $48 \mathrm{~km}$ ) and the mostly intermediate nature of the crust-mantle transition in the Lachlan Orogen could be due to the presence of underplating at the base of the crust, and possibly to the existing thick piles of Ordovician mafic rocks present in the mid and lower crust. Results from numerical modelling of RFs at three seismic stations (CAN, CNB and YNG) suggest that the observed variations with back-azimuth could be related to a complex structure beneath these stations with the likelihood of both a dipping Moho and crustal anisotropy. Our analysis reveals crustal thickening to the west beneath CAN station which could be due to slab convergence. The crustal thickening may also be related to the broad Macquarie volcanic arc, which is rooted to the Moho. The crustal anisotropy may arise from a strong N$\mathrm{S}$ structural trend in the eastern Lachlan Orogen and to the preferred crystallographic orientation of seismically anisotropic minerals in the lower and middle crust related to the paleo-Pacific plate convergence.
\end{abstract}

KEY WORDS: crustal thickness, Moho, seismic anisotropy, Lachlan Orogen, RF, seismic structure, crustal complexity.

\section{INTRODUCTION}

The Middle Paleozoic Lachlan Orogen (450-340 Ma) in southeastern Australia (Figure 1a-c) was accreted to the Precambrian core of the continent in a sequence of stages (e.g. Collins 2002a; Direen \& Crawford 2003; Gray $\&$ Foster 2004). There is ongoing debate as to the exact causes and the nature of accretion. The main reasons are the complexity of the crustal structure of the Lachlan Orogen, and the limited constraints on the crustal structure (particularly on the lower crust). Indeed, only a few deep seismic refraction and reflection profiles have been conducted in the region (e.g. Finlayson et al. 1980, 2002; Direen et al. 2001; Glen et al. 2002). Most onshore refraction profiles date from the 1960s to 1980s (see e.g. Kennett et al. 2011). The crustal structure is constrained in few locations from passive seismic experiment: receiver function (RF) studies (Shibutani et al. 1996; Clitheroe et al. 2000; Kennett et al. 2011). An anisotropic upper, middle and lower crust was well imaged in previous seismic reflection data (Direen et al. 2001; Glen et al. 2002) and the seismic interface between the crust and the mantle was interpreted as not flat (Finlayson et al. 2002; Glen et al. 2002).

In this paper, we bring new constraints on the complex crustal structure in the Lachlan Orogen and particularly in the Canberra region, where we have three permanent stations quite close to each other: CAN at Mt Stromlo, CNB in Kowen Forest and YNG at Young. We also exploit the portable station SO01 to the west near Lake Cargelligo. We show evidence for both crustal anisotropy and a dipping Moho in an area south of the earlier seismic reflection studies.

*Corresponding author: fabrice.fontaine@univ-reunion.fr

() 2013 Geological Society of Australia 
(a)

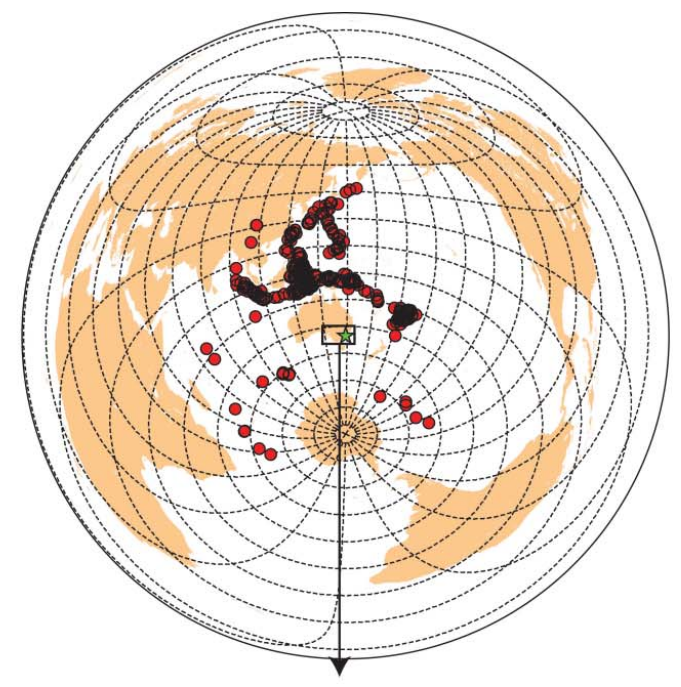

(b)

(c)
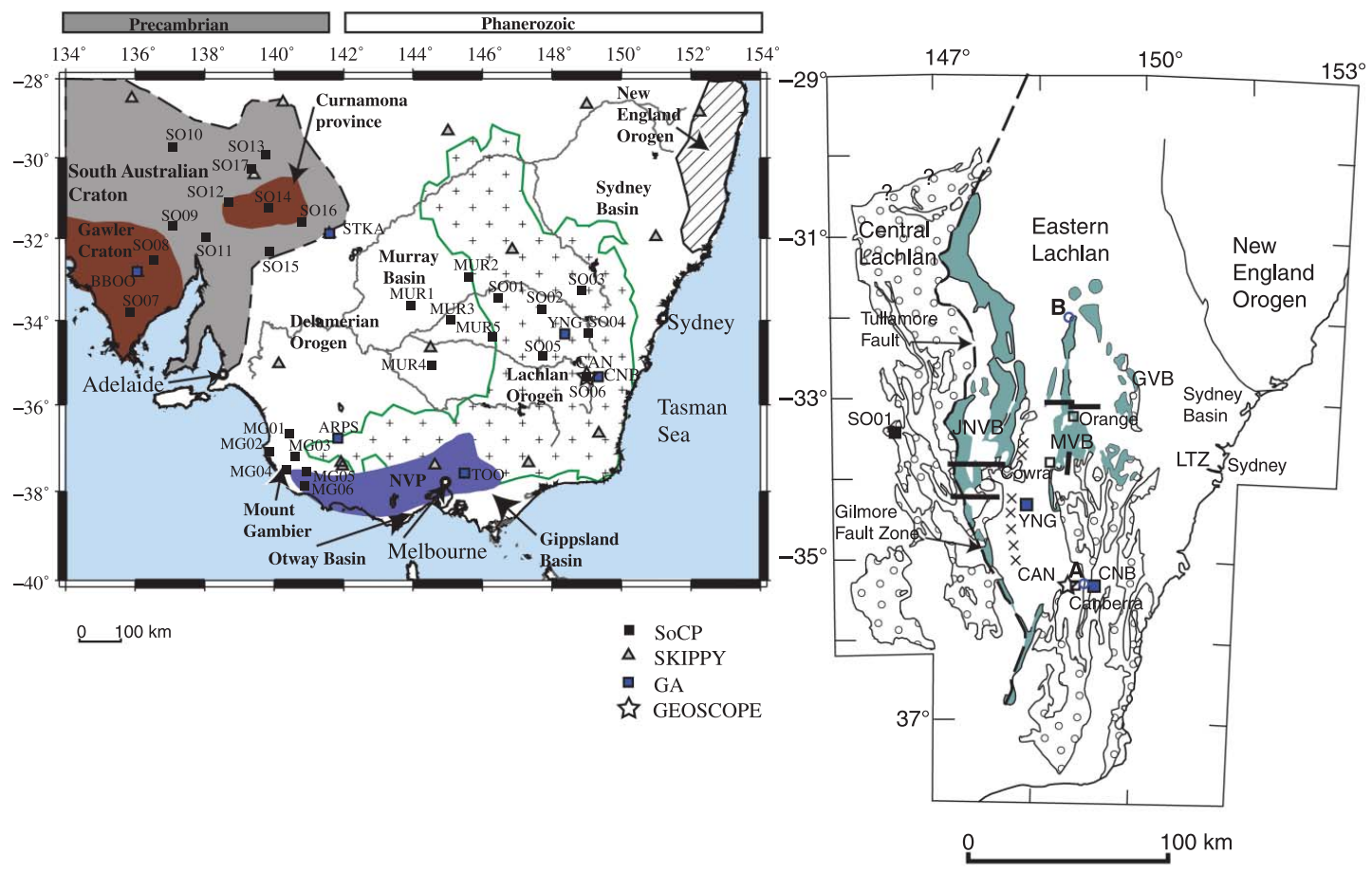

Macquarie Arc

$\times \times$ MORB volcanics

Craton-derived turbidites

Seismic reflection lines

AB Extremities of recording sites

from a wide-angle seismic profile

Broad-band seismic networks:

- SoCP

- GA

岸 GEOSCOPE

Figure 1 (a) Location of the 323 events used for receiver functions analysis at station CAN. The rectangle shows the limits of southeastern Australia and the star represents the location of CAN station. (b) Simplified geological map of southeastern Australia modified from Gray \& Foster (2004) with the location of the SoCP (Southern Cratons to Paleozoic) seismic network and the permanent seismic stations from Geoscience Australia (GA) and GEOSCOPE networks. Key to marked feature: NVP, Newer Volcanic Province. (c) Simplified map of the Lachlan Orogen (modified from Glen et al. 2002 and Finlayson et al. 2002). The three elements of the Ordovician Macquarie Arc are shown, the Junee-Narromine Volcanic Belt (JNVB), Molong Volcanic Belt (MVB), Gulong Volcanic Belt (GVB). LTZ is the Lachlan Transverse Zone. Seismic lines show the location of reflection profiles (Direen et al. 2001; Glen et al. 2002). A and B are the location of the extremities of the refraction profile from Finlayson $e t$ al. (2002). 


\section{DATA ANALYSIS (CAN, CNB, YNG AND SO01 STATIONS)}

The RF technique depends on the analysis of the conversions between seismic wave types and reverberations following the onset of major seismic phases, commonly the first arriving $P$ wave from distant earthquakes. The sequence of secondary arrivals carries information about the structure beneath the recording station. The effects of the source, and the major part of the propagation path, can be eliminated by deconvolving the vertical component of motion by the radial component directed along the great circle to the source (Langston 1977, 1979). The resulting radial $R F$ is then dominated by $P$-to- $S$ conversions and crustal multiples that are diagnostic of the nature of crustal structure.

Many of the methods of RF analysis are based on the assumption that the structure beneath the seismic station can be adequately represented by horizontal stratification, with either uniform layers or gradient zones separated by discontinuities in seismic wavespeed at which conversions arise between $P$ and $S$ waves. We have used three different styles of analysis that exploit various features of the RF waveform, and emphasise different crustal features: crustal thickness, presence of intra-crustal seismic discontinuities, nature of the Moho, $V_{\mathrm{P}} / V_{\mathrm{S}}$ ratio, dipping structure and anisotropy.

\section{H-K stacking method for Moho depth and average crustal properties}

The seismic reverberations in the crust and the delays between $P$ and $S$ waves can constrain crustal thickness and the compressional wave/shear-wave-velocity ratio $\left(V_{\mathrm{P}} / V_{\mathrm{S}}\right)$. At stations where both the Pms (the $P$-to-S conversion at the Moho) and the PpPms (the first Moho multiple) phases are observed, we use a robust grid-search stack procedure (Zhu \& Kanamori 2000) to determine the mean Moho depth and mean crustal $V_{\mathrm{P}} / V_{\mathrm{S}}$ ratio (for details see the supplementary materials). This approach depends on good knowledge of the mean crustal velocity. For southeastern Australia we have good constraints from seismic refraction work (Drummond \& Collins 1986) and employ an average crustal velocity $V_{\mathrm{P}}=$ $6.65 \mathrm{~km} / \mathrm{s}$ (for station CAN, see Figure 2; for station CNB, see Figure 3; and for station SO01, see Figure 4). We use stacks of all RFs across all back-azimuths, and select only events with signal-to-noise ratio (SNR) $\geq 5$ in order to increase the visibility of multiple phases.

\section{Nonlinear waveform inversion for RF}

The radial RFs at each seismic station were stacked for a set of back-azimuths, with a narrow range of ray parameters based on the following procedure (see Fontaine et al. 2013 for further details):

(1) Select the quadrant (back-azimuths between $\mathrm{N} 0^{\circ}$ and $\mathrm{N} 90^{\circ}$, between $\mathrm{N} 90^{\circ}$ and $\mathrm{N} 180^{\circ}$, between $\mathrm{N} 180^{\circ}$ and $\mathrm{N} 270^{\circ}$, between $\mathrm{N} 270^{\circ}$ and $\mathrm{N} 360^{\circ}$ ) with the highest number of RFs.

(2) Compute $p_{\text {median }}$ : the median of the ray parameters of all seismic events in this interval.
(3) Select events with a ray parameter $=p_{\text {median }} \pm 0.004$ $(\mathrm{s} / \mathrm{km})$. Most data come from seismogenic belts surrounding Australia, and this narrows down the range of useful ray parameters. For example, the useful ray parameter range for station CAN is between 0.067 and $0.075 \mathrm{~s} / \mathrm{km}$.

(4) Stack the RFs selected in the previous step. Only mutually coherent RFs are used for stacking, and we focused on obtaining the most basic information assuming a horizontally layered structure. Before each stack, we checked the coherency of individual RFs using the cross-correlation matrix approach from Tkalčić et al. (2011), and we found an insignificant difference of crustal thickness derived from the NA inversion of a single RF and the inversion of the stacked RF at the same station.

We have used a nonlinear inversion method, the Neighbourhood Algorithm (NA, Sambridge 1999), to determine the crust and upper mantle structure that can explain the observed radial RF with a 1-D seismic velocity model. During the inversion, the synthetic radial RF for the layered structure was calculated using the ThomsonHaskell matrix method (Thomson 1950; Haskell 1953). The full effects of free-surface reverberations and conversions were modelled. During the inversion, as in the work of Shibutani et al. (1996), the model was parameterised in terms of six layers: a sediment layer, basement layer, upper crust, middle crust, lower crust and uppermost mantle with internal velocity gradients and the possibility of discontinuities at the boundaries. We used similar bounds for the 24 parameters to those of Shibutani et al. (1996), Clitheroe et al. (2000) and Fontaine et al. (2013) (e.g. Fontaine et al. 2013, table 1). The inversion is carried out in terms of 24 parameters, the $V_{\mathrm{S}}$ values at the top and bottom of the gradient zone, the thickness of the gradient zone and the $V_{\mathrm{P}} / V_{\mathrm{S}}$ ratio in each zone. The inclusion of the $V_{\mathrm{P}} / V_{\mathrm{S}}$ ratio serves primarily to allow for some of the effects of the sedimentary layer beneath the stations with no a priori information (Bannister et al. 2003). The NA method combines a Monte Carlo search technique and the properties of the Voronoi geometry in parameter space to find an ensemble of the best-fitting models and performs a global optimisation. We present the results of inversions through density plots of the best 1000 datafitting $S$-velocity models generated by the NA (see, e.g. Figures 5,6 ). The model with the best fit to the data is plotted in red. The set of 24 parameters in the inversion are relatively well constrained, but the $S$-velocity distribution is better constrained by the inversion than the $V_{\mathrm{P}} / V_{\mathrm{S}}$ ratio.

\section{Analysis for anisotropy and dipping layers}

For isotropic and horizontally layered structures, the theoretical transverse RFs are zero. For either an isotropic dipping layer or an anisotropic layer, the transverse RFs do not vanish. The polarity of the direct $P$ phase and the Pms phase on the transverse component can constrain the direction of discontinuity dip (Peng \& Humphreys 1997). A periodicity of $360^{\circ}$ with respect to back-azimuth in Pms amplitude can be caused by a 
(a)

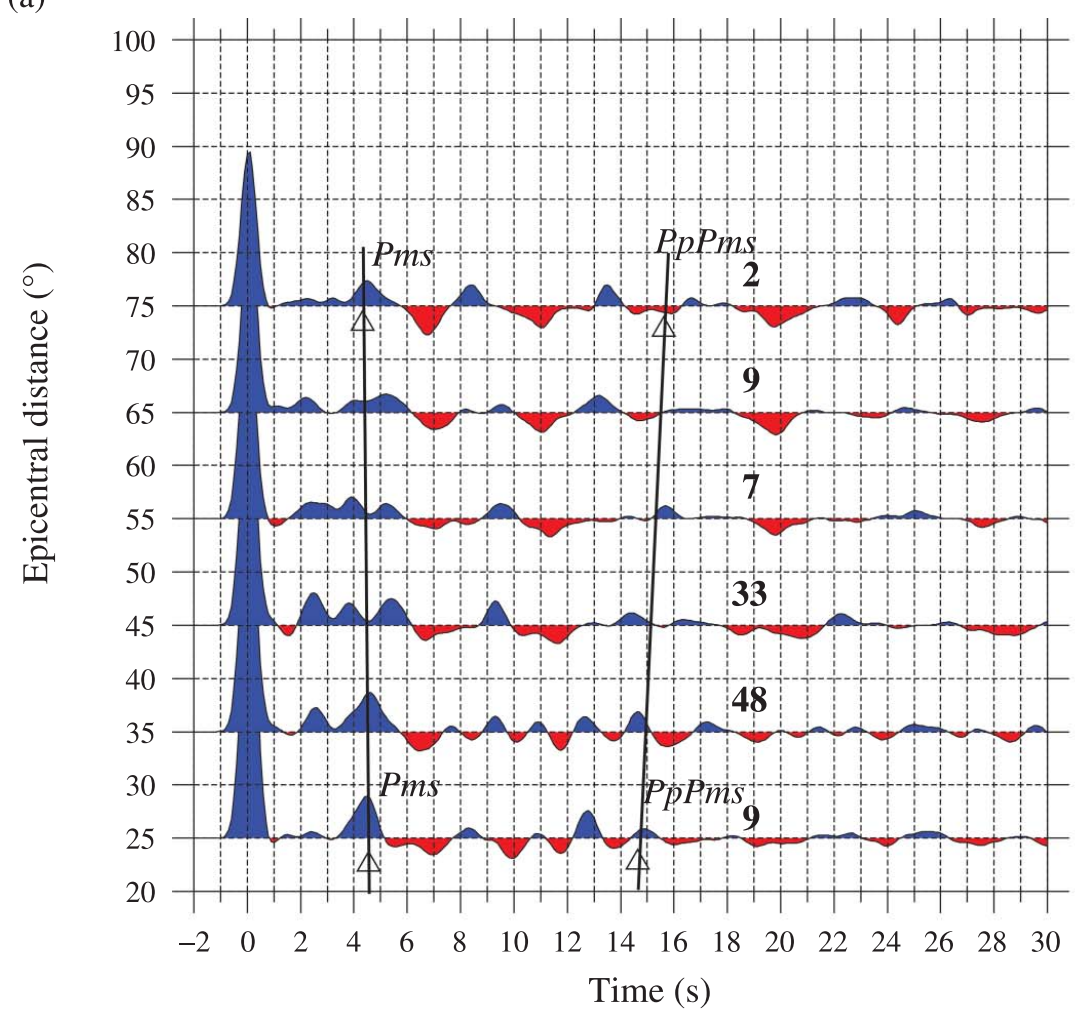

station CAN : 108 traces

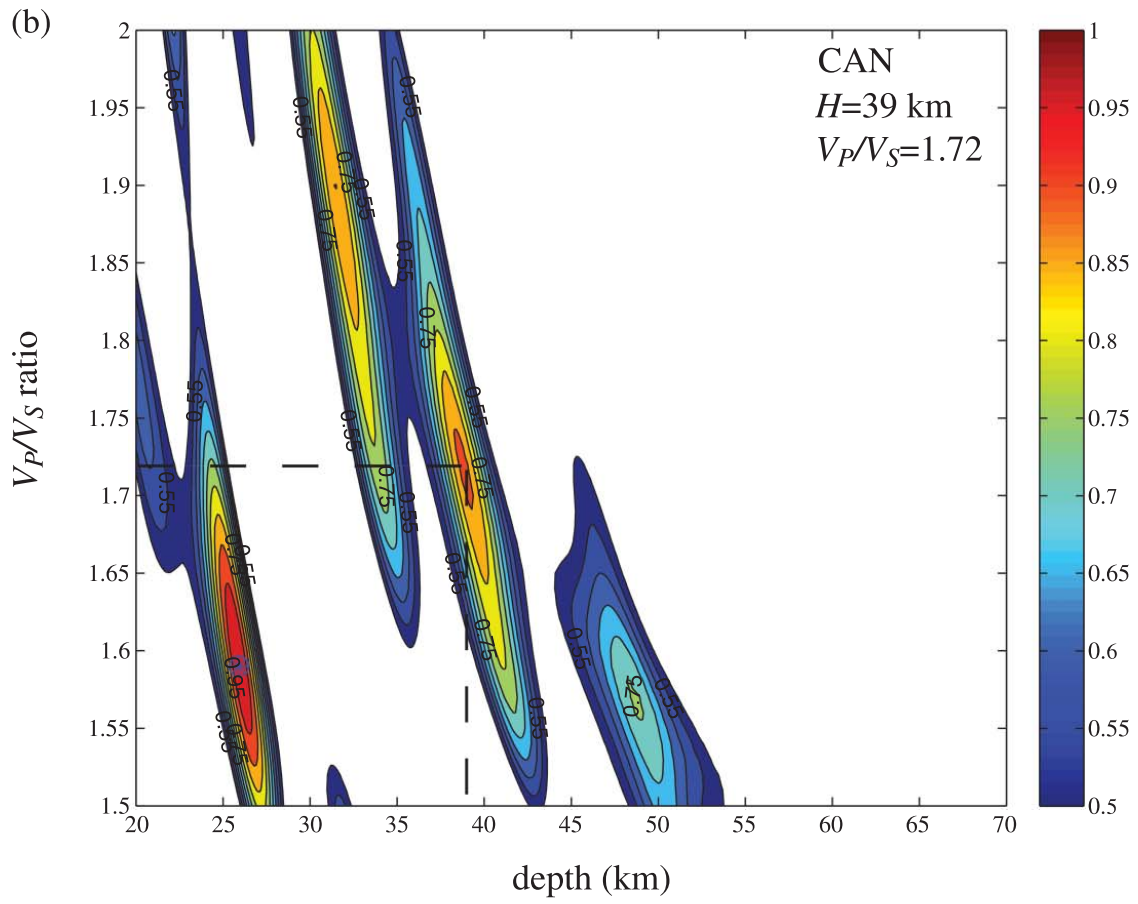

Figure 2 Results from the H-K stacking analysis for RFs (Zhu \& Kanamori 2000). (a) Stack over $10^{\circ}$ epicentral distance intervals of radial RFs at CAN seismic station. Numbers on right side are numbers of RFs stacked for each distance interval. Triangles indicate computed arrival times of phases Pms and PpPms for the best solution. (b) Normalised amplitudes of the stack over all back-azimuths along the travel time curves corresponding to the Pms and PpPms phases at CAN. Although $H=26 \mathrm{~km}$ and $V_{\mathrm{P}} / V_{\mathrm{S}}=1.58$ correspond to a global maximum, there is also a local maximum in the H-K stack at values that are more physically realistic and more consistent with other modelling methods: $H=39 \mathrm{~km}$ and $V_{\mathrm{P}} / V_{\mathrm{S}}$ $=1.72$. The estimated values of $H$ and $V_{\mathrm{P}} / V_{\mathrm{S}}$ strongly depend on which peak is identified as $P m s$ by the stacking method. dipping interface or by an anisotropic layer with a tilted axis of symmetry. In contrast, a $180^{\circ}$ periodicity in $P m s$ amplitude is produced by crustal anisotropy with transverse anisotropy and a horizontal symmetry axis.

At station CAN, radial and transverse RFs show evidence (Figure 7) for both the presence of crustal anisotropy and a dipping Moho. We employ the NA as implemented by Frederiksen et al. (2003) for the joint inversion of the radial and transverse RFs for models with both anisotropy and dipping structure. We assumed the presence of both a dipping Moho and an anisotropic lower, middle and upper crust with hexagonal symmetry. 
(a)

CNB
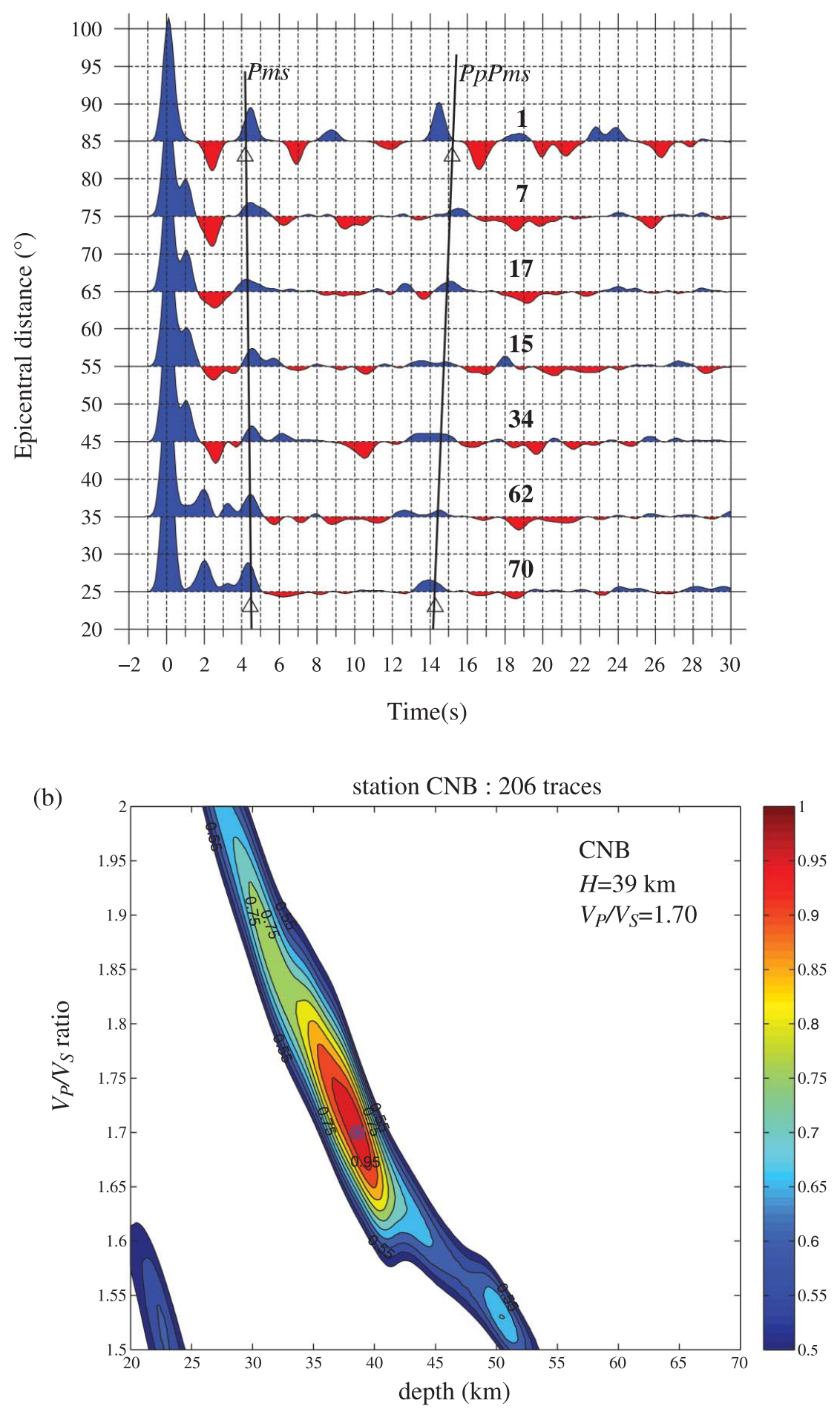

$3(a, b)$ Figure details are as shown as Figure $2(\mathrm{a}, \mathrm{b})$ for station CNB. $H=39 \mathrm{~km}$ and $V_{\mathrm{P}} / V_{\mathrm{S}}=1.70$.

Hexagonal symmetry is specified by a symmetry axis orientation and five independent elastic constants for a total of seven free parameters. Hexagonal symmetry can occur in Earth from several different mechanisms (e.g. Sherrington et al. 2004). Effective hexagonal anisotropy may be due to:

- thin alternating layers of fast and slow material when the seismic wavelength is substantially greater than the layer;
- aligned cracks within an isotropic rock; and

- preferred mineral alignments if there is a single preferred orientation, with random orientations in the other two coordinates, even when the individual minerals have higher order symmetry.

Although cracks may be important at shallow depths, several studies have found that aligned minerals are the most likely cause of seismic anisotropy in rocks at middle and lower crustal depths (e.g. Siegesmund et al. 1989; 


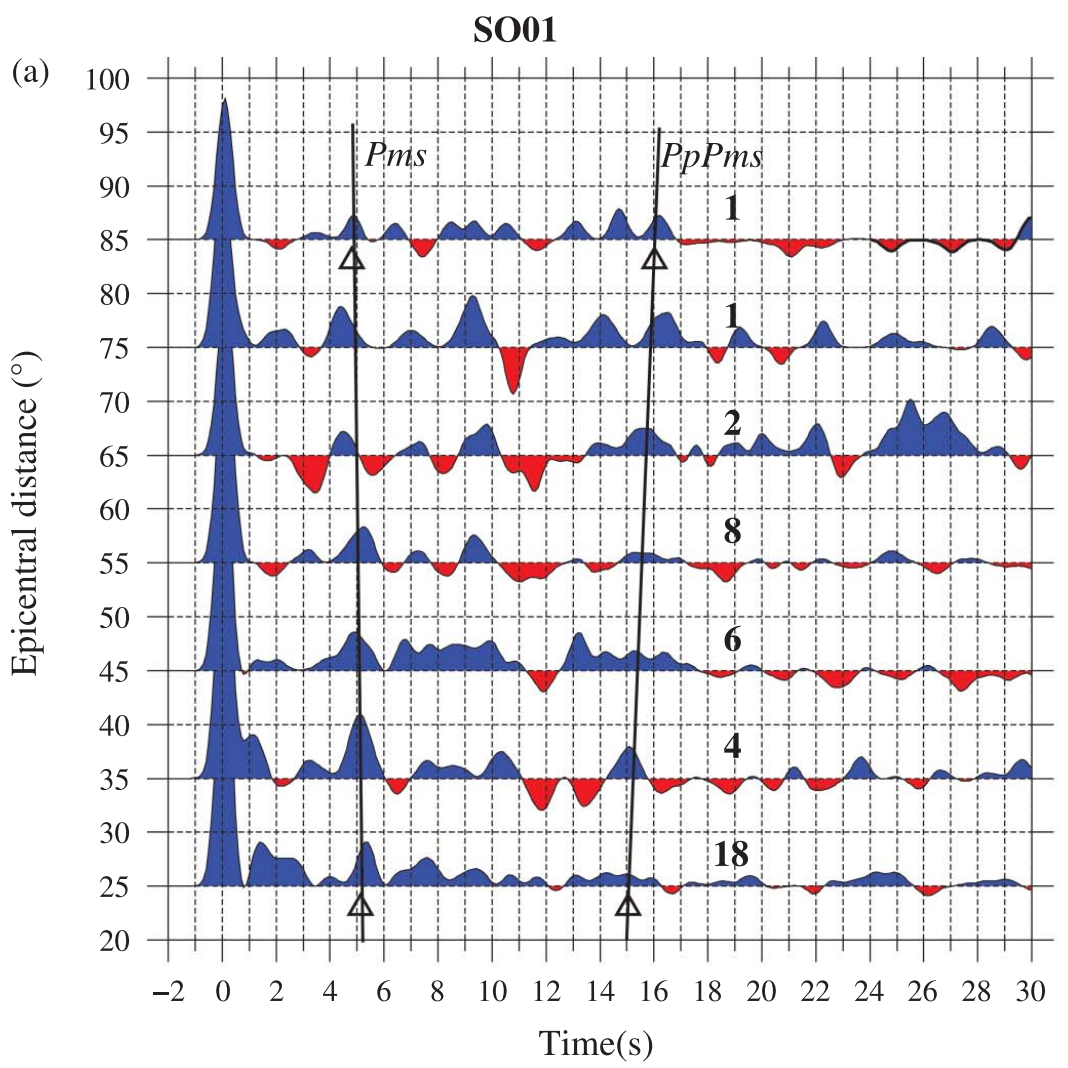

(b)

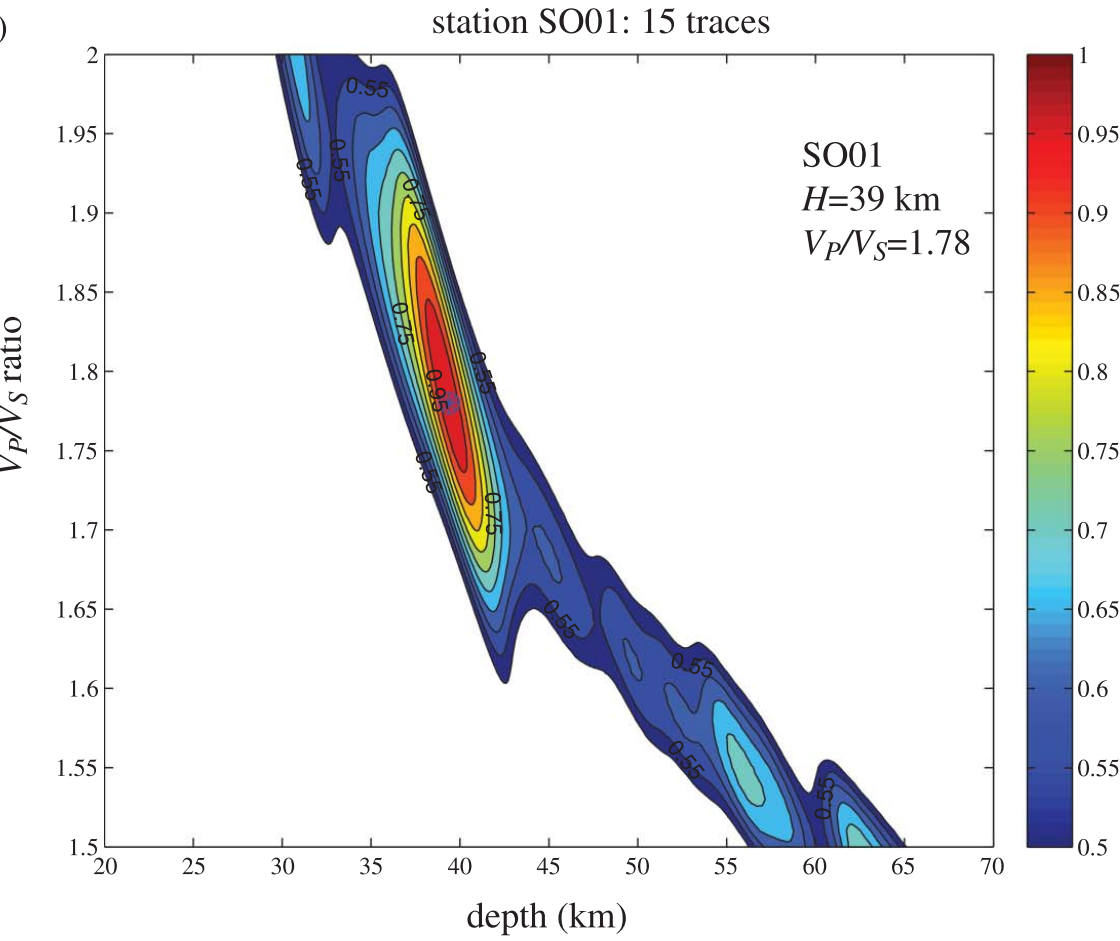

Figure $4(\mathrm{a}, \mathrm{b})$ Figure details are as shown as Figure $2(a, b)$ for station SO01. $H=39 \mathrm{~km}$ and $V_{\mathrm{P}} / V_{\mathrm{S}}$ $=1.78$.

Kern \& Wenk 1990; Barruol \& Kern 1996; Weiss et al. 1999). Most natural lower continental rocks show a hexagonal type of anisotropy (Weiss et al. 1999).

The synthetic seismograms used in the inversion are computed using a ray-based approach (Frederiksen \& Bostock 2000). Multiples were not computed primarily to minimise computation time, which could take several hours if all multiples are included (e.g. Sherrington et al. 2004). The inversion starts by randomly choosing some number of models from a multidimensional model parameter space. The user defines the size of the model parameter space by defining the range of each model parameter. Synthetic seismograms are computed for each model and cross-correlation based misfits between 

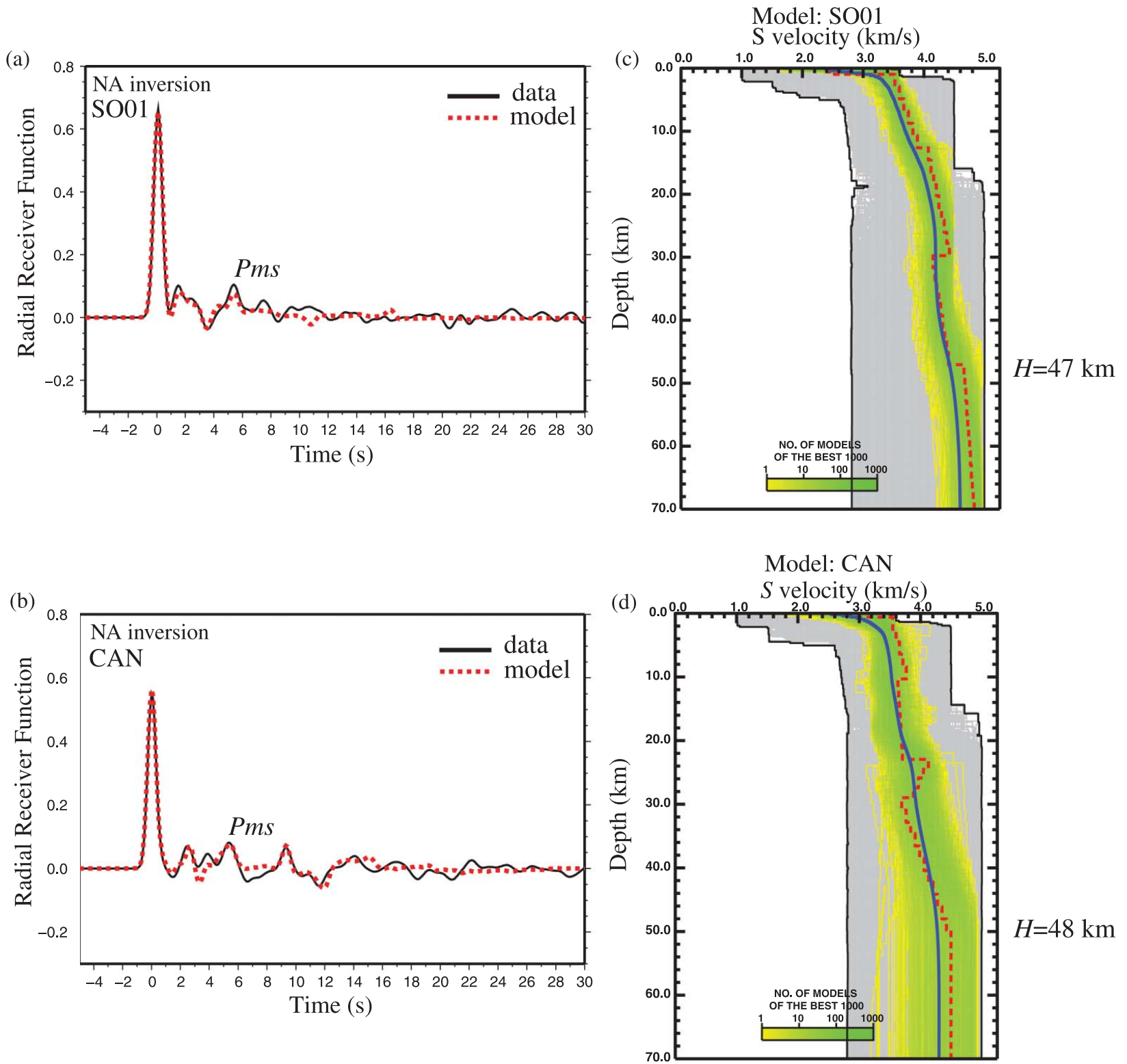

Figure $5(a, b)$ Comparison between the observed average and the predicted radial RFs from the NA inversion at SO01 and CAN. (c, d) The 1-D shear-wave-velocity models obtained from the NA inversion at SO01 and CAN. All the 22600 models searched in the NA inversion are shown as the grey shaded area. The best 1000 models are shown as a yellow and green area, the colour being logarithmically proportional to the number of models. The colour scale shows the increase in data fit from yellow to green. A dashed red line represents the best data-fitting model. A solid blue line represents the average model of the best 1000 fitting models. $0 \mathrm{~km}$ depth corresponds to the station elevation.

data and the synthetics are calculated. As the number of iteration increases, the smaller regions of model parameter space containing low misfit are searched in more detail. We consider two anisotropic layers in the crust and one isotropic sedimentary layer on the top with less than $2 \mathrm{~km}$ thickness to simplify the computation. We allowed the level of velocity anisotropy to vary between 0 and $10 \%$. Savage (1998) proposed that anisotropy should be small in the upper crust based on results from local earthquake shear-wave splitting studies with less than $4 \%$ anisotropy in the top few kilometres of the crust (Crampin 1994). Layer thicknesses and velocity ranges were fixed using constraints from Finlayson et al. (2002) and Glen et al. (2002).

\section{RESULTS}

\section{$\mathrm{H}-\mathrm{K}$ stacking results for Moho depth and $V_{\mathrm{P}} / V_{\mathrm{S}}$}

We were able to use the H-K stacking method to constrain crustal thickness and the $V_{\mathrm{P}} / V_{\mathrm{S}}$ ratio at four stations (SO01, CNB, YNG and CAN); at the others (in the Lachlan Orogen), we could not observe clear multiples. Chevrot \& van der Hilst (2000) have previously pointed out the absence of clear multiples in this region. At CAN station, we obtain the best stack for an apparent crustal thickness of $26 \mathrm{~km}$ (Figure 2b); however, the associated $V_{\mathrm{P}} / V_{\mathrm{S}}$ value of 1.58 is almost implausible as a significant portion of the crust would have to be composed of quartz 
(a)

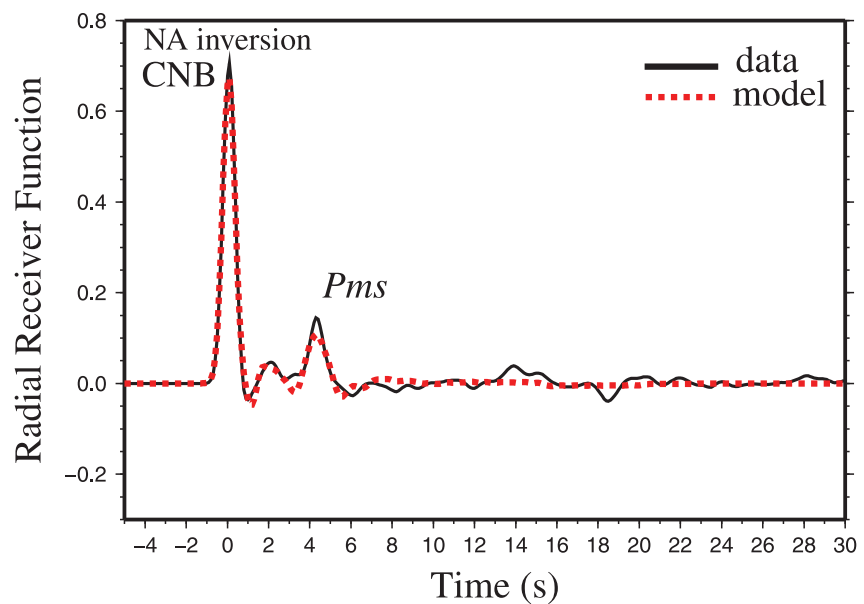

(b)

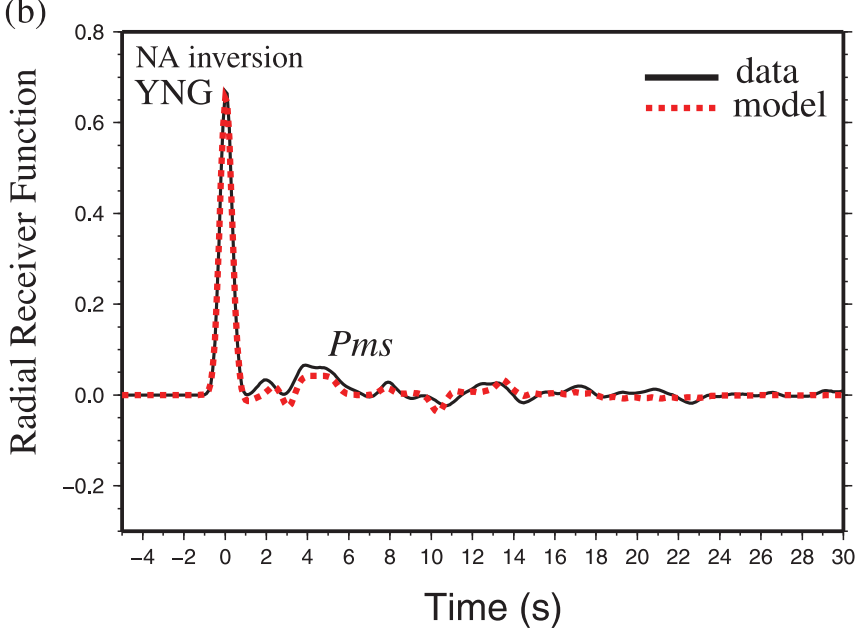

(c)

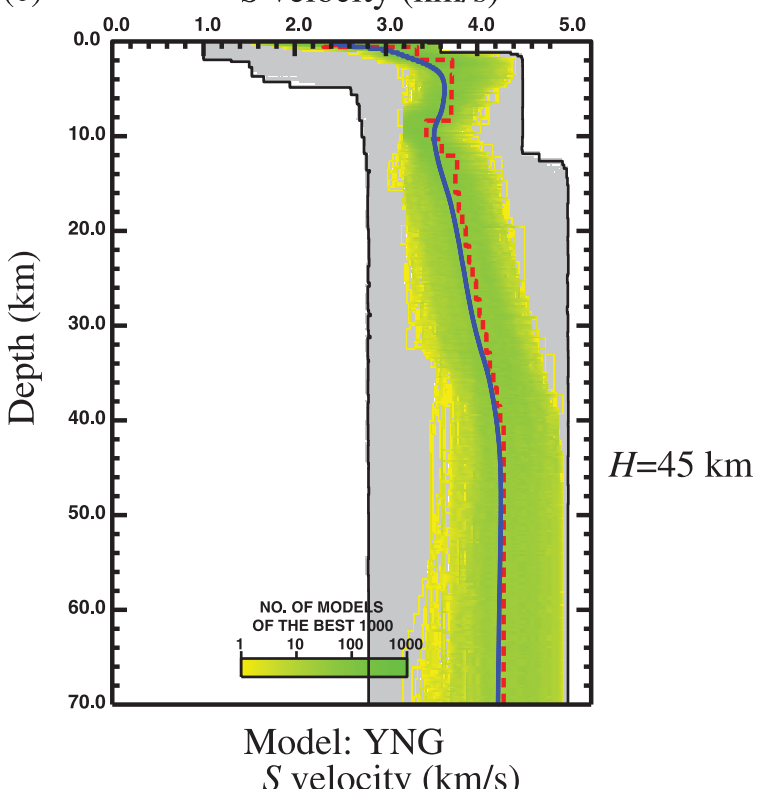

Figure $6(\mathrm{a}, \mathrm{b})$ Comparison between the observed average and the predicted radial RFs from the NA inversion at CNB and YNG. (c, d) The 1-D shear-wave-velocity models obtained from the NA inversion at CNB and YNG. Figure details are as shown as Figure $5(a, b)$.

(Christensen 1996). Interestingly, we observe a local maximum for a depth of $39 \mathrm{~km}$ with $V_{\mathrm{P}} / V_{\mathrm{S}}=1.72$, which is much closer to the results at CNB and YNG seismic stations. These values are physically more realistic and more consistent with the results from the other modelling methods that we used in this study; and also similar to those by Chevrot \& van der Hilst (2000) who obtained a Moho depth of $37 \mathrm{~km}$ and a $V_{\mathrm{P}} / V_{\mathrm{S}}$ ratio value of 1.72 at $\mathrm{CAN}$. The reason that the $\mathrm{H}-\mathrm{K}$ stacking concentrates on a shallower seismic discontinuity than the Moho, determined by the other RF methods, is the assumption of a single layered crust and a sharp base of the crust at a station where the crust-mantle transition is gradational. The crustal thickness estimates from H-K stacking are: $39 \pm 2 \mathrm{~km}$ at station CNB (Figure $3 \mathrm{~b}$ ), $35 \pm 6 \mathrm{~km}$ at station YNG (see Supplementary Papers Figure 1) and $39 \pm 2 \mathrm{~km}$ at station SO01 (Figure $4 \mathrm{~b}$ ). We obtain $V_{\mathrm{P}} / V_{\mathrm{S}}$ ratios of $1.72 \pm 0.08,1.70 \pm 0.03,1.75 \pm 0.11$ and $1.78 \pm 0.04$ for stations CAN, CNB, YNG and SO01, respectively.

\section{Nonlinear inversion results}

To constrain the Moho depth, we have used the NA (Sambridge 1999) considering five layers with gradients in the crust at all stations. We take the base of the transition to mantle velocities to define the Moho depth, in order to be in accordance with previous RF studies (e.g. Clitheroe et al. 2000), which produce Moho depths close to estimates from seismic refraction studies (Collins 1991; Collins et al. 2003). Here, we take the upper mantle velocity for this Phanerozoic region to be $V_{\mathrm{P}} \geq 7.6 \mathrm{~km} / \mathrm{s}$ following Giese (2005), which means that $V_{\mathrm{S}} \geq 4.3$ 
CAN, observed receiver functions

(a) Radial

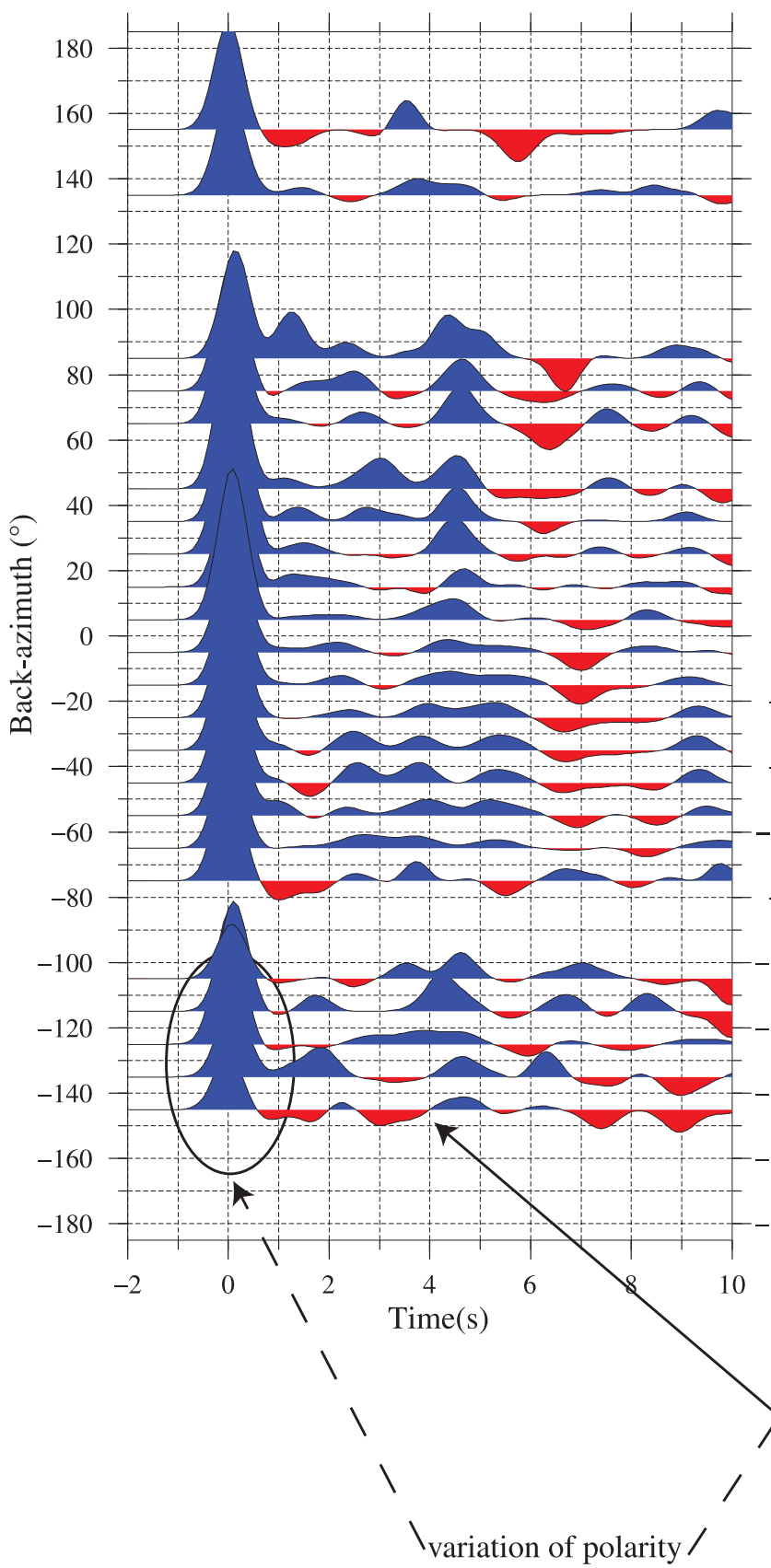

(b) Transverse

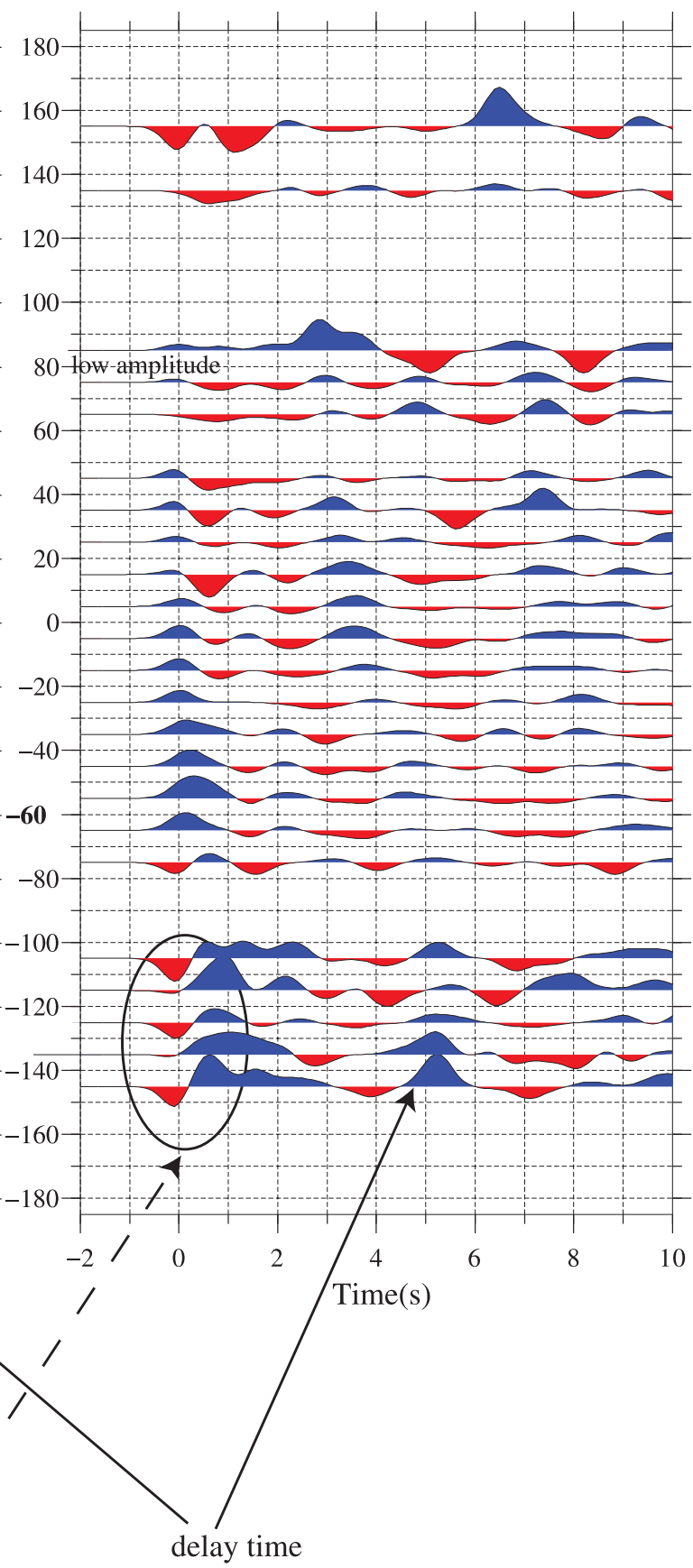

Figure 7 (a) Radial RFs vs back-azimuth at CAN. (b) Transverse RFs vs back-azimuth at CAN. Arrows and circles illustrate delay time and variation of polarity related to dipping and anisotropic effects.

$4.4 \mathrm{~km} / \mathrm{s}$ for $V_{\mathrm{P}} / V_{\mathrm{S}}$ ratios in the range $1.73-1.77$ at the base of the gradient. In previous Australian studies, Clitheroe et al. (2000) used similar values $\left(V_{\mathrm{P}}>7.6 \mathrm{~km} / \mathrm{s}\right)$ for RFs, and Collins et al. (2003) used for their compilation, with both refraction and $\mathrm{RF}$ results, a value of $V_{\mathrm{P}}>$ $7.8 \mathrm{~km} / \mathrm{s}$. Fontaine et al. (2013) confirmed that using $V_{\mathrm{P}}$ $\geq 7.6 \mathrm{~km} / \mathrm{s}$ (i.e $V_{\mathrm{S}} \geq 4.3-4.4 \mathrm{~km} / \mathrm{s}$ assuming a $V_{\mathrm{P}} / V_{\mathrm{S}}$ ratio in the range 1.73-1.77) and the base of the zone of velocity gradients provides good agreement between crustal thicknesses estimated from seismic reflection profiles and those obtained from RF inversion.

Figures 5 and 6 present the shear-wave-velocity models from the NA inversion and data fits at SO01, CAN, $\mathrm{CNB}$ and YNG. Figure 8 compares the average shearwave-velocity models beneath CAN, CNB and YNG. We obtained similar depths to the Moho using different methods: the base of a gradient at $48 \mathrm{~km}$ from the NA algorithm (Figure 5 and Supplementary Papers Figure 2) 


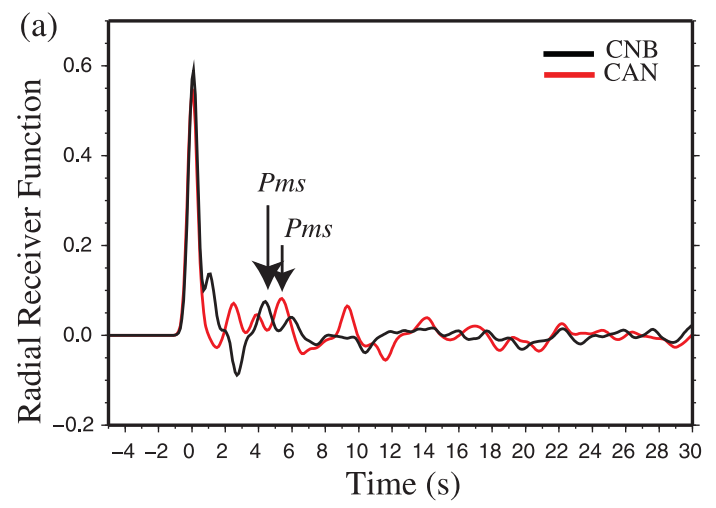

(b) NA inversion

YNG (NNW of CAN station)

Average 1-D $S$ wave velocity model

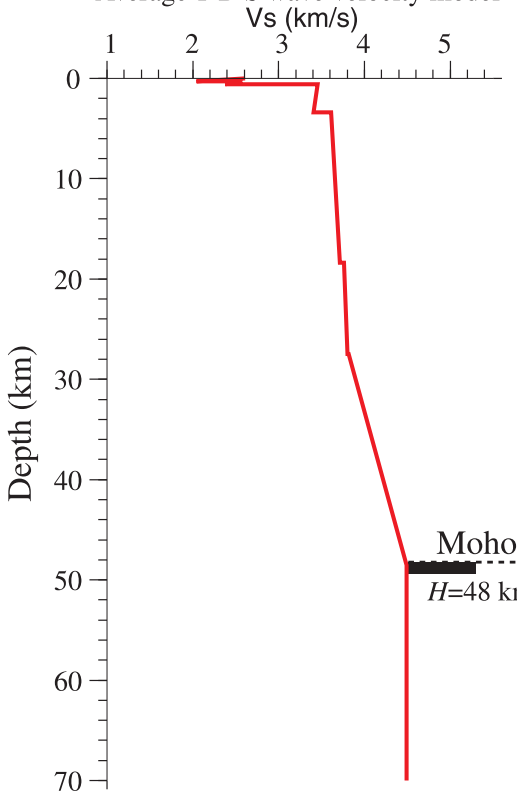

\section{CAN}

Average 1-D $S$ wave velocity model Vs $(\mathrm{km} / \mathrm{s})$
CNB (E of CAN station)

Average 1-D $S$ wave velocity model Vs $(\mathrm{km} / \mathrm{s})$
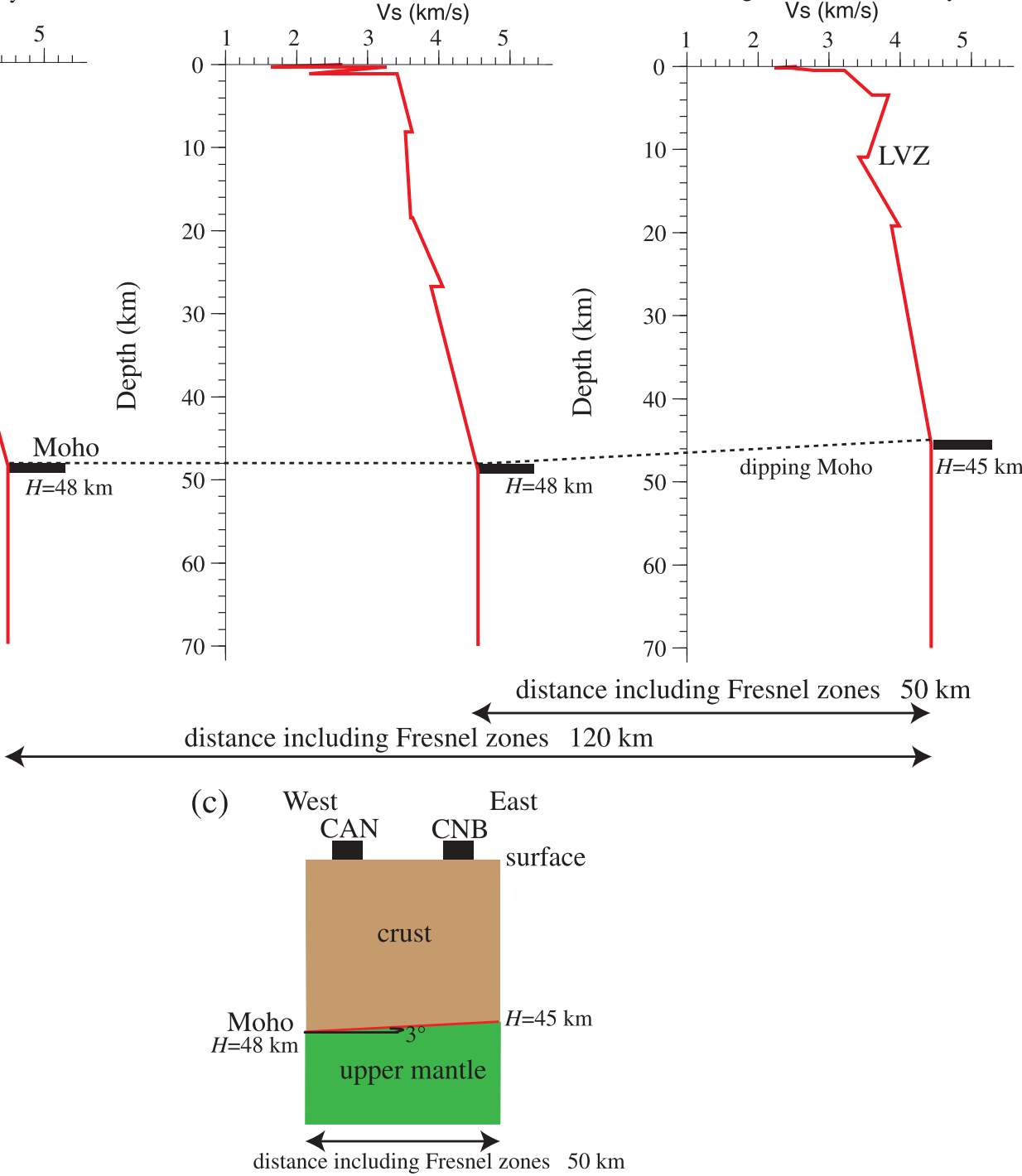

Figure 8 (a) Comparison between observed average radial RFs at CNB and CAN. The Pms phase arrives earlier at CNB suggesting a thinner crust than below CAN. (b) Synthesis of 1-D shear-wave-velocity models derived from teleseismic earthquakes near CAN station. The red lines are the average models of the best 100 fitting models derived for each station in the NA inversion. The Moho is interpreted to be the base of the high-velocity gradient zone, shown in black shading. We connected by a dashed line seismic discontinuities, which are similar beneath two adjacent seismic stations. (c) Cartoon showing our interpretation of the 1-D shear-wave-velocity models at CAN and CNB stations. This interpretation is also consistent with observed variations of RFs with back-azimuths at CAN. 
and 43-49 km from an alternative grid search (see Supplementary Papers) with a single sharp discontinuity.

The Moho depths show a generally thick crust beneath this part of the Lachlan Orogen ranging from $34 \mathrm{~km}$ in the west and up to $48 \mathrm{~km}$ (Figure 9). Taking into account crustal thickness estimates from previous studies (e.g. Clitheroe et al. 2000; Collins et al. 2003; Kennett et al. 2011; Fontaine et al. 2013), the maximum crustal thickness is thicker beneath the Lachlan Orogen than beneath the Gawler Craton. Fontaine et al. (2013) found a maximum crustal thickness of $45 \mathrm{~km}$ beneath the Gawler Craton, whereas we found a value of $48 \mathrm{~km}$ beneath CAN and YNG stations in the Lachlan Orogen. The uncertainty of a crustal thickness value is mainly between 2 and $3 \mathrm{~km}$ (Fontaine et al. 2013). The lower crustal structures obtained at CAN and YNG correspond to a broad velocity transition zone at the Moho and a crustal thickness around $48 \mathrm{~km}$. The results of Moho depths (45 and $47 \mathrm{~km}$ ) from NA inversion at CNB and SO01 are compatible with results obtained from the grid search stacking (Moho depths of $39 \pm 2 \mathrm{~km}$ and $39 \pm$ $2 \mathrm{~km})$.
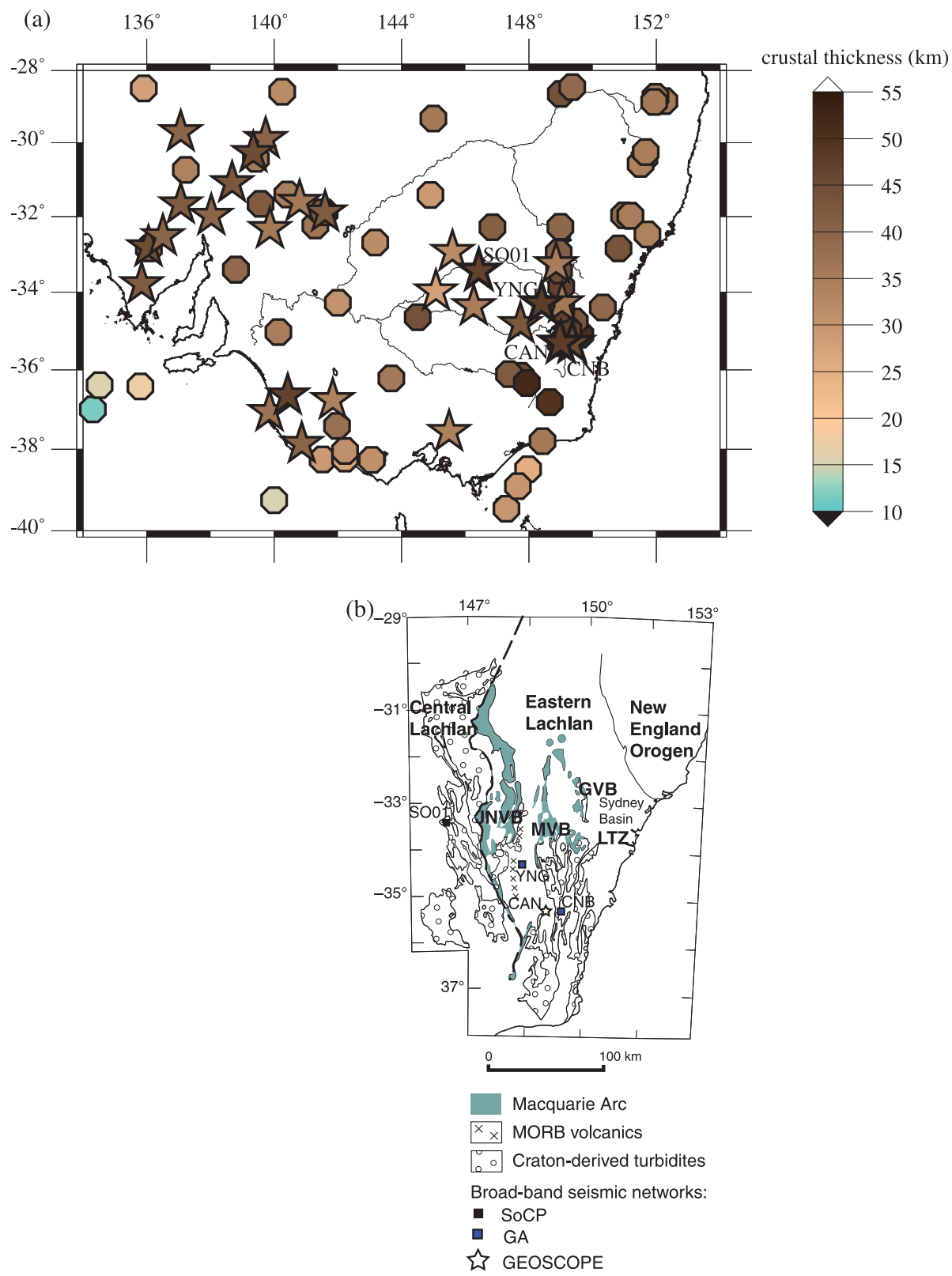

Figure 9 (a) Location map of the depth of the crust-mantle seismic discontinuity beneath southeastern Australia. Two different symbols are used: stars represent location and crustal thicknesses from a previous study (Fontaine et al. 2013) and this study (heavier outline). Octagons show results from previous studies (Collins 1991; Shibutani et al. 1996; Clitheroe et al. 2000; Collins et al. 2003; Saygin 2007). (b) Simplified tectonic architecture of the Lachlan Orogen (modified from Glen et al. 2002 and Finlayson et al. 2002). The three elements of the Ordovician Macquarie Arc are shown, the Junee-Narromine Volcanic Belt (JNVB), Molong Volcanic Belt (MVB), Gulong Volcanic Belt (GVB). LTZ is the Lachlan Transverse Zone. 


\section{Detailed modelling of RFs and their variations at permanent stations (CAN, CNB and YNG)}

The RFs at CAN and YNG display a $360^{\circ}$ periodicity of the direct $P$ phase in back-azimuth (Figures 7, 10), which suggests a dipping Moho structure or a tilted anisotropic layer. In the case of an isotropic medium with a dipping crustal discontinuity, the dip direction is the direction for which the amplitude of the direct $P$-wave on the transverse component goes from negative to positive values (Peng \& Humphreys 1997). At CAN, the dip direction would be $270^{\circ}$; this would imply a strike of $180^{\circ}$ for the discontinuity.

The relative behaviour of the radial and transverse RFs at CAN suggests the presence of anisotropy: we observe a clear difference in arrival time between the radial and transverse Pms phase at CAN (Figure 7), which is a strong indication of splitting of the shear wave converted at the Moho. The observed delay time is $0.21 \mathrm{~s}$ for the Pms phase for RFs with a back-azimuth of $65^{\circ}$.

At CAN, we have good coverage of back-azimuth, and the patterns of variation in amplitude on the transverse RFs, relative to the direct $P$ phase suggest the presence of both dipping structure and crustal anisotropy (Figure 7). The back-azimuthal coverage is not as good at CNB, but the transverse RFs (Figure 11) are not negligible and suggest the presence of either an isotropic dipping discontinuity and/or anisotropic crustal layer. Interestingly, the RFs variations show a $360^{\circ}$ periodicity of the Pms phase at station YNG (Figure 10) suggesting the presence of a dipping Moho or crustal anisotropy with a dipping axis of symmetry. The amplitude of the direct $P$ phase is negative on the transverse components for back-azimuths between $-65^{\circ}$ and $95^{\circ}$, whereas it is positive on the radial components. This feature is not expected for a simple isotropic crust with a dipping

YNG, observed receiver functions

(a) Radial

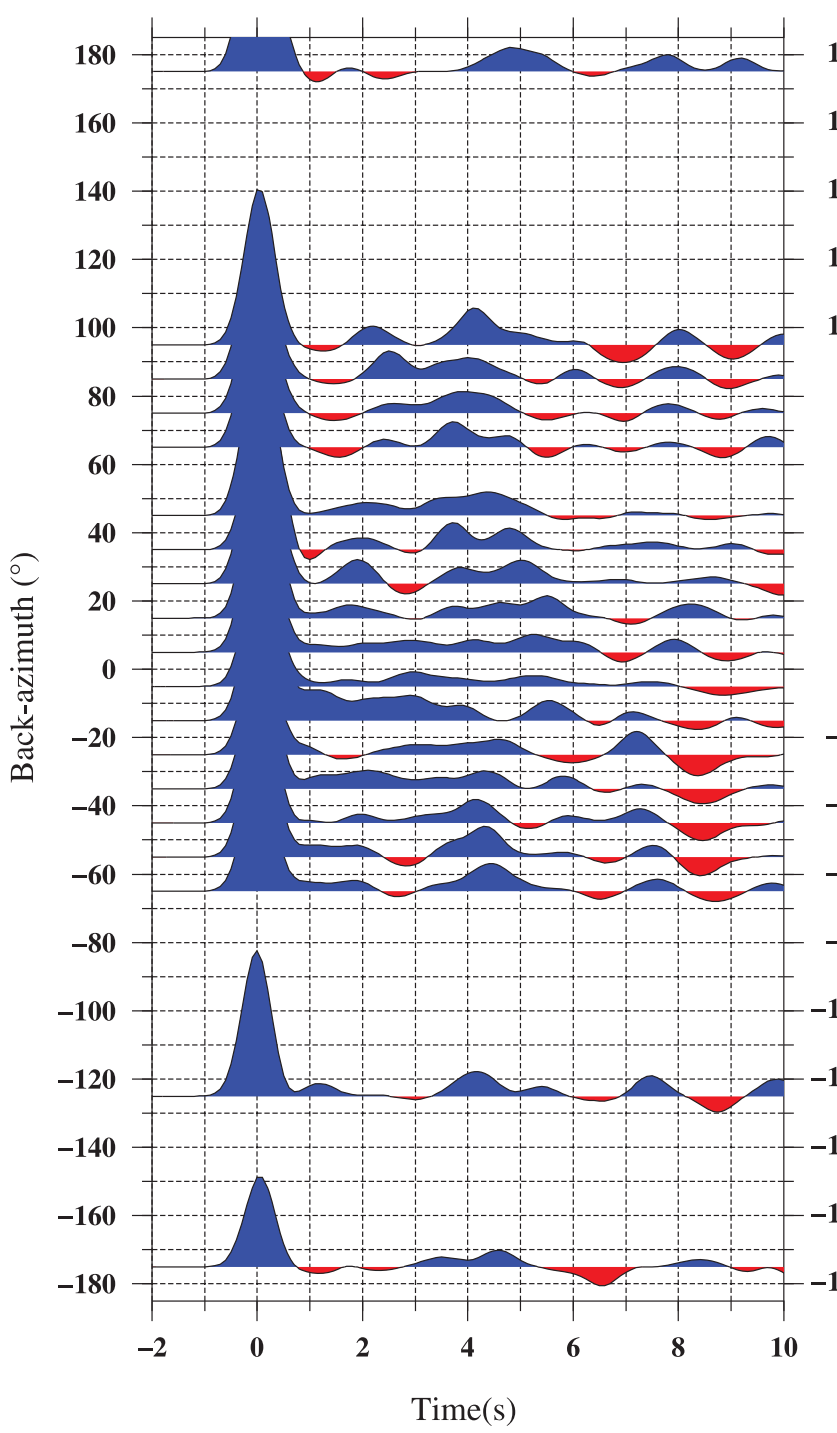

(b) Transverse

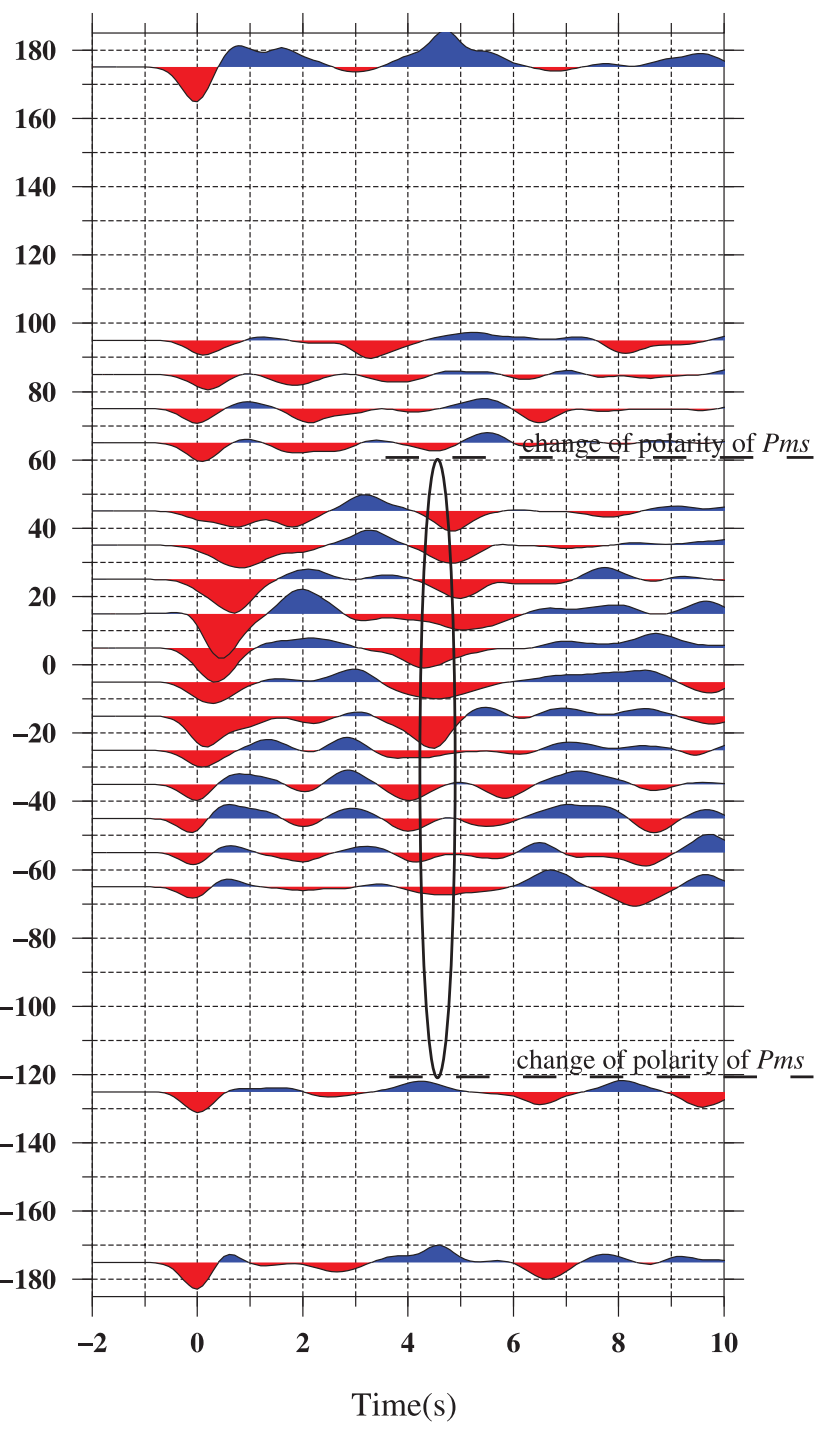

Figure 10 (a) Radial RFs vs back-azimuth at YNG. (b) Transverse RFs vs back-azimuth at YNG. 


\section{CNB, observed receiver functions}

(a) Radial

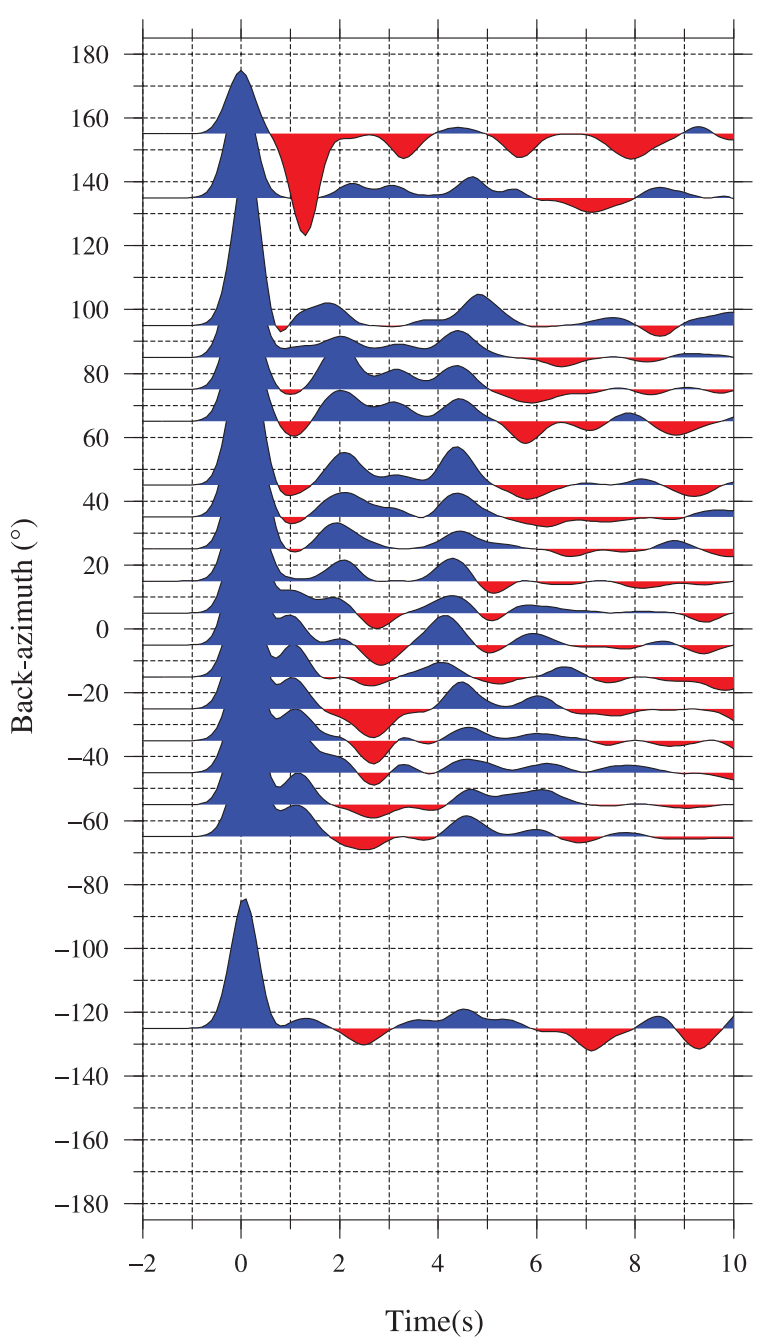

(b) Transverse

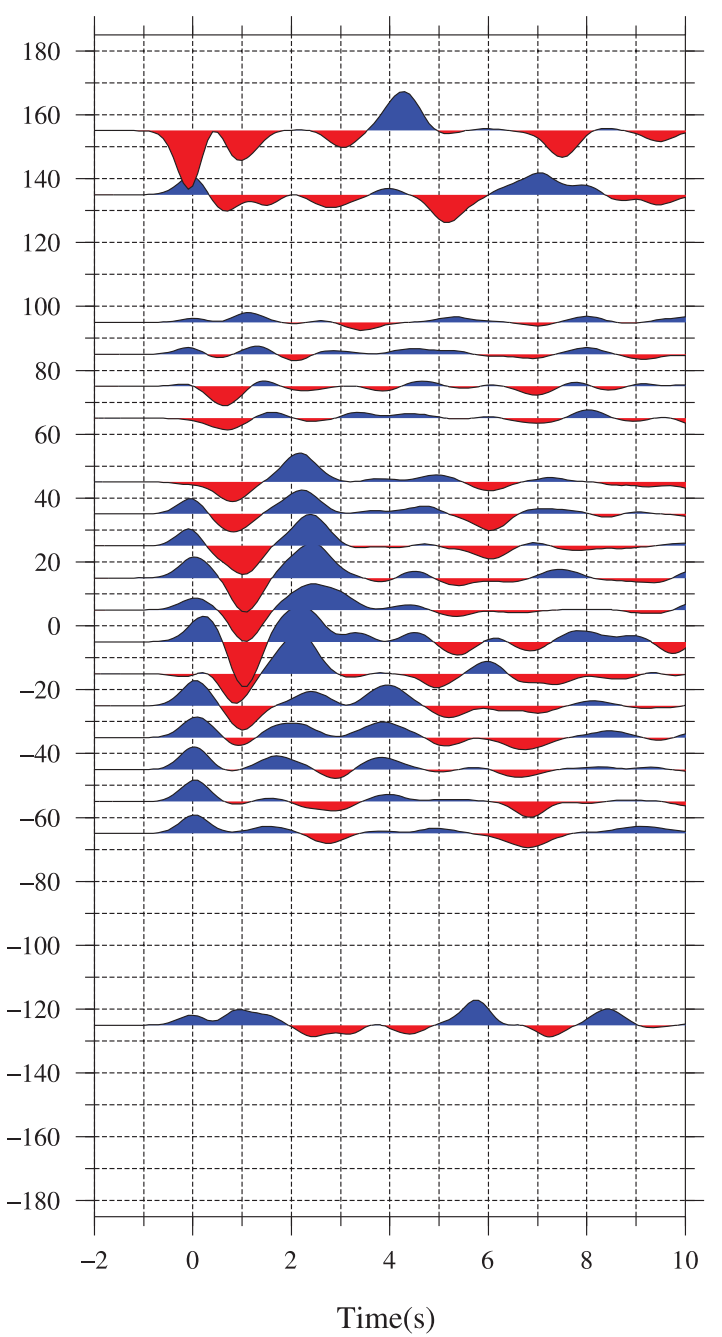

Figure 11 (a) Radial RFs vs back-azimuth at CNB. (b) Transverse RFs vs back-azimuth at CNB.

discontinuity and suggests the presence of crustal anisotropy with a dipping symmetry axis (see Savage 1998, figure $5 \mathrm{~b}$ ). The presence of a negative pulse on the transverse component for the direct $P$ phase might be due to the fact that both the upper and the lower crust are anisotropic (see Savage 1998, figure 5b, c). The amplitude of the transverse component is quasi-null for back-azimuths near $85^{\circ}$. Such RF variations with back-azimuth could be related to crustal anisotropy with a slow axis direction close to $85^{\circ}$ and thus the fast axis direction near $-5^{\circ}$ (i.e $355^{\circ}$ ), which is consistent with the fast axis direction obtained at station CAN. This E-W direction of the slow axis is also consistent with the highest amplitude of the Pms phase on the radial components for a back-azimuth of $95^{\circ}$. We note a change of polarity of the Pms phase on the transverse component at $-120^{\circ}$ (i.e $240^{\circ}$ ) and at $60^{\circ}$. This change of polarity with a $360^{\circ}$ periodicity may be related to a Moho dipping in the WSW direction $\left(240^{\circ}\right)$.

Although RF inversion is both nonlinear and nonunique, the observed features (polarity and delay) of the direct $P$ phase and the $P m s$ phase on radial and transverse components are compatible with $R F$ synthetics that we computed for simple dipping anisotropic structures with the inversion method of Frederiksen et al. (2003). The average of the best 100 fitting models from the 18000 models generated during the inversion of RFs is given in Table 1. This average model is our preferred model based on the global optimisation used for the inversion. Table 2 gives the best-fitting model from all models generated during the inversion of RFs. The bestfitting model at station CAN is presented in Figure 12 as synthetic radial and transverse RFs $v s$ back-azimuth. We present in the Table 3 the range of values associated with anisotropy and a dipping Moho determined for the best 100 models. Both the strike and the dipping angle values obtained for the Moho (Tables 1-3) are similar to the values obtained from seismic reflection profiles in the eastern Lachlan Orogen (Glen et al. 2002) north of the Canberra region. The dipping angle is also consistent with Moho depth determined in this study at CAN and $\mathrm{CNB}$ stations from the NA inversion of radial RF. 
Table 1 Average anisotropic model of the best 100 models generated during the neighbourhood inversion of radial and transverse receiver functions at $\mathrm{CAN}$.

\begin{tabular}{|c|c|c|c|c|c|c|c|c|c|}
\hline Thickness (km) & $\rho\left(\mathrm{g} / \mathrm{cm}^{3}\right)$ & $<V_{\mathbf{P}}>(\mathbf{k m} / \mathbf{s})$ & $<V_{\mathrm{S}}>(\mathrm{km} / \mathrm{s})$ & $P$ anis. & $S$ anis. & Azimuth $\left(^{\circ}\right)$ & $P l\left({ }^{\circ}\right)$ & Strike $\left({ }^{\circ}\right)$ & $\operatorname{Dip}\left({ }^{\circ}\right)$ \\
\hline 1.76 & 2.625 & 5.550 & 2.640 & 0 & 0 & $\mathrm{~N} / \mathrm{A}$ & $\mathrm{N} / \mathrm{A}$ & 0 & 0 \\
\hline 19.00 & 2.612 & 6.163 & 3.620 & 6.0 & 0.3 & 6 & 21 & 0 & 0 \\
\hline 26.00 & 2.652 & 6.105 & 3.997 & 9.9 & 0.3 & 327 & 3 & 0 & 0 \\
\hline Half-space & 3.223 & 8.214 & 4.582 & 0 & 0 & $\mathrm{~N} / \mathrm{A}$ & $\mathrm{N} / \mathrm{A}$ & 172 & 3 \\
\hline
\end{tabular}

Thickness is layer thickness, $\rho$ is layer density. Azimuth is the direction of the fast axis $\left(^{\circ}\right.$ ); $P l$, plunge of the fast axis. $P$ anis., percentage anisotropy for $P$ wave; $S$ anis., percentage anisotropy for $S$ wave; $\left\langle V_{\mathrm{P}}\right\rangle$, average $P$-wave velocity; $\left\langle V_{\mathrm{S}}\right\rangle$, average $S$-wave velocity; the remaining parameter $\eta$ is an anisotropic parameter and it is fixed at 1.03 (Farra et al. 1991; Frederiksen \& Bostock 2000).

Twenty parameters (in bold) were searched during the inversion. The remaining parameters are fixed from previous studies constraints (Finlayson et al. 2002; Glen et al. 2002). Layers are listed from top to bottom. Strike and dip refer to the upper interface of the layer. The down-dip direction is $90^{\circ}$ clockwise of strike.

The Moho is dipping to the east of CAN, and the fast symmetry axis direction is between 0 and $13^{\circ}$ in the upper anisotropic layer and between 309 and $352^{\circ}$ in the lower anisotropic layer. The axis of symmetry dips in the range $0-7^{\circ}$ in the upper anisotropic layer and $16-24^{\circ}$ in the lower anisotropic layer. Anisotropy with a dipping symmetry axis can produce a pattern identical to that caused by a dipping interface in an isotropic medium. It is difficult to distinguish between a dipping axis of symmetry and a dipping interface for a single station from RFs alone (Savage 1998) or from particle motion alone (Schulte-Pelkum et al. 2001).

\section{DISCUSSION}

Our analysis of the RFs provides information on the nature of the crust through the $V_{\mathrm{P}} / V_{\mathrm{S}}$ ratio, on the nature of the Moho and constraints on dipping structures and anisotropy.

\section{$V_{\mathrm{p}} / V_{\mathrm{s}}$ ratios}

We observe significant variations in the $V_{\mathrm{P}} / V_{\mathrm{S}}$ ratio across the region. At SO01, the $V_{\mathrm{P}} / V_{\mathrm{S}}$ value obtained from the $\mathrm{H}-\mathrm{K}$ stacking is high $\left(V_{\mathrm{P}} / V_{\mathrm{S}}\right.$ is $\left.\sim 1.78\right)$ in the crust suggesting a mafic composition compatible with mafic granulite rocks (Christensen 1996). The $V_{\mathrm{P}} / V_{\mathrm{S}}$ ratio is around 1.7 at CAN and CNB and 1.75 at YNG compatible with the presence of granite-gneiss beneath CAN and CNB and biotite gneiss beneath YNG. At SO01 this would be the down dip extension of mafic rocks imaged and modelled in Direen et al. (2001), (Figure 4a, b). At
CAN and CNB stations, the $V_{\mathrm{P}} / V_{\mathrm{S}}$ values are compatible with mafic orthogneisses or mafic granulite inferred in the lower crust from a wide-angle seismic profile in the southern Lachlan Orogen (Finlayson et al. 2002). Whereas at YNG station the $V_{\mathrm{P}} / V_{\mathrm{S}}$ value is compatible with paragneisses inferred from seismic reflection profiles performed across the Junee-Narromine Volcanic Belt in the vicinity of this seismic station (Direen et al. 2001).

\section{Nature of the crust-mantle transition}

Using the character of the crust-mantle transition (Figures 5c, d, 6c, d) we classify the Moho transition zone as sharp $\leq 2 \mathrm{~km}$, intermediate $2-10 \mathrm{~km}$ or broad $>10 \mathrm{~km}$, as suggested by Shibutani et al. (1996). Our Moho estimates lie at the base of any gradient (in conformity with earlier work; e.g. Clitheroe et al. 2000). The crust-mantle boundary is deep and mostly intermediate in character beneath the Lachlan Orogen. These results are consistent with previous observations (e.g. Shibutani et al. 1996; Clitheroe et al. 2000; Collins et al. 2003; Fontaine et al. 2013). Finlayson et al. (2002) pointed out a sharper velocity gradient to the upper mantle velocity in the north than in the south. The authors preferred interpretation was that there may be a velocity transition zone, $1-3 \mathrm{~km}$ thick, at the base of the lower crust rather than a step increase in velocity, with a thicker, more diffuse zone in the south and thus closer to CAN and CNB stations (point A of Figure 1c). The broad velocity transition zone at the Moho obtained for both CAN and CNB are thus in agreement with the interpretation of Finlayson et al. (2002). The thickened crust beneath the Lachlan Orogen was

Table 2 Parameters from the best model of the 18000 models generated during the neighbourhood inversion of radial and transverse receiver functions at CAN station.

\begin{tabular}{lccccccccc}
\hline Thickness $(\mathbf{k m})$ & $\boldsymbol{\rho}\left(\mathbf{g} / \mathbf{c m}^{\mathbf{3}}\right)$ & $\left\langle\boldsymbol{V}_{\mathbf{P}}>\mathbf{( k m} / \mathbf{s}\right)$ & $\left\langle\boldsymbol{V}_{\mathbf{S}}>(\mathbf{k m} / \mathbf{s})\right.$ & $\boldsymbol{P}$ anis. & $\boldsymbol{S}$ anis. & Azimuth $\left(^{\circ}\right)$ & $\boldsymbol{P l}\left(\mathbf{(}^{\circ}\right)$ & Strike $\left(^{\circ}\right)$ & Dip $\left(^{\circ}\right)$ \\
\hline 1.76 & 2.622 & 5.550 & 2.640 & 0 & 0 & N/A & N/A & 0 & 0 \\
19.00 & 2.612 & 6.193 & 3.643 & 6.2 & 0.2 & 5 & 18 & 0 & 0 \\
26.00 & 2.651 & 6.102 & 3.998 & 9.9 & 0.2 & 323 & 3 & 0 & 0 \\
Half-space & 3.221 & 8.220 & 4.580 & 0 & 0 & N/A & N/A & 170 & 3 \\
\hline
\end{tabular}

Thickness is layer thickness, $\rho$ is layer density. Azimuth is the direction of the fast axis $\left(^{\circ}\right) ; P l$, plunge of the fast axis. $P$ anis., percentage anisotropy for $P$ wave; $S$ anis., percentage anisotropy for $S$ wave; $\left\langle V_{\mathrm{P}}\right\rangle$, average $P$-wave velocity; $\left\langle V_{\mathrm{S}}\right\rangle$, average $S$-wave velocity; the remaining parameter $\eta$ is an anisotropic parameter and it is fixed at 1.03 (Farra et al. 1991; Frederiksen \& Bostock 2000). Strike and dip refer to the upper interface of the layer. 
Model: CAN, synthetics

(a) Radial

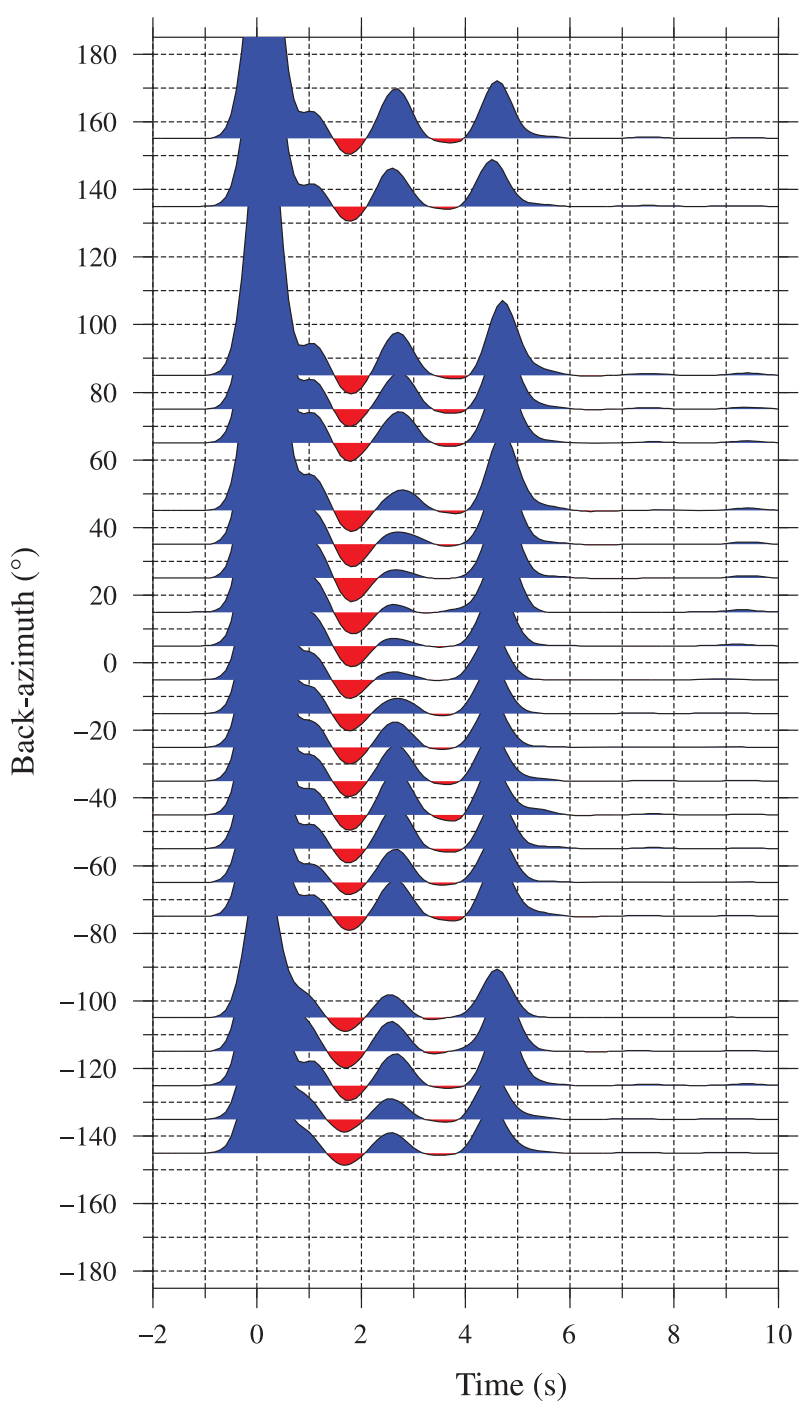

(b) Transverse

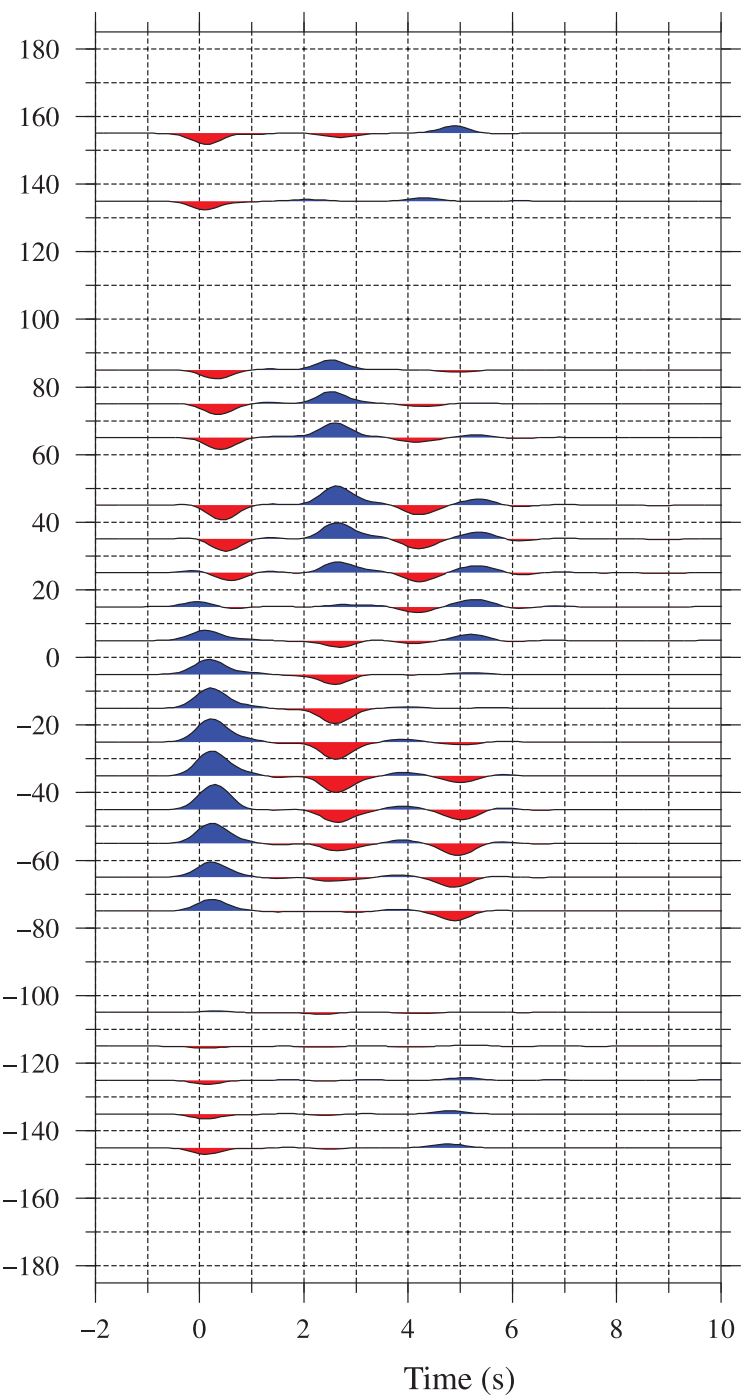

Figure 12 (a) Synthetic radial RFs $v s$ back-azimuth at CAN for the best-fitting model (see Table 2). (b) Synthetic transverse RFs $v s$ back-azimuth at CAN for the best-fitting model.

Table 3 Range of inverted parameter values at CAN station related to anisotropy and a dipping Moho determined for the best 100 models.

\begin{tabular}{llc}
\hline Second layer & $P$ anis. & $5-7$ \\
& $S$ anis. & $0-2$ \\
& Azimuth $\left(^{\circ}\right)$ & $0-13$ \\
Third layer & $P l\left(^{\circ}\right)$ & $0-7$ \\
& $P$ anis. & $9-10$ \\
& $S$ anis. & $0-1$ \\
Half-space & Azimuth $\left(^{\circ}\right)$ & $309-352$ \\
& $P l\left(^{\circ}\right)$ & $16-24$ \\
& Strike $\left(^{\circ}\right)$ & $170-176$ \\
& Dip $\left(^{\circ}\right)$ & $2-4$ \\
\hline
\end{tabular}

Azimuth is the direction of the fast axis $\left(^{\circ}\right) ; P l$, plunge of the fast axis. $P$ anis., percentage anisotropy for $P$ wave; $S$ anis., percentage anisotropy for $S$ wave. Strike and dip refer to the upper interface of the layer. already established by previous studies (e.g. Shibutani et al. 1996; Clitheroe et al. 2000; Collins et al. 2003; Fontaine et al. 2013). The variations in the crustal thickness and the intermediate and broad transition between crust and mantle beneath the Lachlan Orogen may be related to the presence of underplating at the base of the crust (e.g. Drummond \& Collins 1986; Shibutani et al. 1996; Gray \& Foster 2004; Fontaine et al. 2013). They may also result from existing thick piles of Ordovician mafic rocks present in the mid and lower crust (Glen et al. 2002). As proposed in previous studies (O'Reilly 1989; Cull et al. 1991; McDonough et al. 1991) based on heat-flow models and the predominant mafic lower crustal rock types identified in xenoliths, magmatic and tectonic underplating has been a significant mechanism in the crustal growth. Finlayson et al. (2002) and Glen et al. (2002) also suggested from a seismic refraction profile the presence of an 
underplated layer near CAN and CNB. Interestingly, the tomographic model from Rawlinson et al. (2010) shows an increase in $P$-wavespeed at the SO01 location and the authors interpret the high velocity zone as a result of the presence of magmatic underplating.

\section{Dipping Moho}

The behaviour of the RFs at CAN suggests a dipping Moho to the west beneath CAN station, and ties in with a thinner Moho at CNB (Figure 8). A dipping Moho was also imaged by previous seismic studies. Finlayson et al. (2002) from a seismic refraction profile and Glen et al. (2002) from a seismic reflection profile show a southerly dip of the Moho. Glen et al. (2002) also show from seismic reflection profiles a west-dipping Moho with a dipping angle between 2 and $3^{\circ}$, which is in agreement with our results. The crustal thickening towards the west might be due to the slab convergence (of the paleo-Pacific plate). The thickening could also be due to the broad semi-autochtonous Macquarie volcanic arc, which is rooted to the Moho. It would be good to have further information from closer to the coast, but such seismic stations suffer from much higher ambient seismic noise and so a long duration of recording is necessary to extract high-quality RF information.

\section{Evidence for anisotropic structure}

Numerical modelling of RFs variations with back-azimuth at CAN suggests the presence of a complex structure beneath the station, with possibly a dipping fast axis of anisotropy. The fast axis direction is close to the $\mathrm{N}-\mathrm{S}$ direction in the middle and lower crust (Table 1). This fast axis orientation is roughly parallel to the direction of extension in the Lachlan Orogen and perpendicular to the direction of convergence. The fast axis direction suggests that the observed anisotropy is closely linked to this direction of convergence. The seismic anisotropy could be related to contraction events in the eastern Lachlan Orogen, which occurred at several periods (at least five) between $450 \mathrm{Ma}$ and $350 \mathrm{Ma}$ (e.g. Collins 2002b). North-south shortening (generally $<5 \%$ ) was interactive with east-west shortening during the Lachlan Orogen evolution (e.g. Gray \& Foster 2004). However, regional structural relationships between northsouth and east-west shortening suggest that the major north-south structural grain of the Lachlan Orogen results from overall east-west shortening (e.g. Gray \& Foster 2004). The anisotropy could be due to a strong N-S structural trend in the eastern Lachlan Orogen, which extends from surface to Moho with a variable dip (e.g. Foster \& Gray 2000; Gray \& Foster 2004) and possibly to the preferred crystallographic orientation of seismically anisotropic minerals in the middle and lower crust (e.g. Siegesmund et al. 1989; Kern \& Wenk 1990; Barruol \& Kern 1996, Weiss et al. 1999). Previous seismic reflection profiles show indications of an anisotropic upper, middle and lower crust (Direen et al. 2001; Glen et al. 2002). Here we clearly identify at CAN seismic anisotropy in the crust from RFs.

From measurements of $P$-wave polarisation $\left(P_{\mathrm{pol}}\right)$ at CAN, Fontaine et al. (2009) proposed the presence of a dipping intra-crustal discontinuity. $P_{\text {pol }}$ measures the horizontal component of the angle by which $P$-wave polarisation deviates from the great-circle path between the source and the receiver. This deviation could be arise from: (i) sensor misorientation, (ii) a dipping seismic discontinuity, (iii) the presence of anisotropy, and (iv) velocity heterogeneities beneath the receiver. The estimate of the direction of the fast axis of anisotropy at CAN made from $P$-wave polarisation by Schulte-Pelkum et al. (2001) is $-16.47^{\circ}$ (i.e $343.53^{\circ}$ ) and by Fontaine et al. (2009) $-12.29^{\circ}$ (i.e. $347.71^{\circ}$ ). These directions are close to the fast axis orientations obtained in the lower anisotropic layer (Table 3) from the modelling of the observed radial and transverse RFs variations with back-azimuth. Fontaine et al. (2009) was able to obtain a good fit using a single isotropic layer model and Snell's Law with a dipping seismic discontinuity in the crust to fit the $P_{\mathrm{pol}}$ measurements instead of using more complexity with multiple layers. However, the pattern of $P_{\mathrm{pol}}$ deviations reported in Fontaine et al. (2009) is also compatible with a fast axis of symmetry azimuth of $\sim 330^{\circ}$ beneath CAN because a tilt of the axis of hexagonal symmetry away from the horizontal breaks down the $180^{\circ}$ periodicity (SchultePelkum et al. 2001). The orientation of $330^{\circ}$ is not far from the fast axis azimuth obtained in the lower anisotropic layer with the $P$ RFs: between 309 and $352^{\circ}$ (Table 3).

Our results suggests the presence of dipping fast axis of symmetry in the middle and lower crust beneath CAN and may explain the apparent isotropy observed in the analysis of $S K S$ splitting at CAN station assuming a horizontal orientation of anisotropy (e.g. Vinnik et al. 1989; Barruol \& Hoffmann 1999; Heintz \& Kennett 2005). Interestingly, Heintz \& Kennett (2005) observed from three shear-wave splitting measurements a fast axis azimuth between $22^{\circ}$ and $55^{\circ}$ at $\mathrm{CNB}$ with a delay time in the range $0.5-0.95 \mathrm{~s}$. They commented on the meaning of such a rapid change in elastic properties in the vicinity of Canberra, on a scale of a few tens of kilometres. Owing to our limited back-azimuthal resolution at $\mathrm{CNB}$ we cannot constrain such a change. However, we do observe clear variations of the RFs on the transverse components between YNG and CAN. The presence of lateral heterogeneities beneath CAN may explain the apparent isotropy observed with splitting measurements at CAN station. The variation of the observed fast axis direction for two different back-azimuths at CNB station (Heintz \& Kennett 2005) with good quality splitting measurements may be due to the presence of multiple layers of anisotropy beneath this station.

\section{CONCLUSION}

We have modelled teleseismic RFs using three different methods (H-K stacking; nonlinear inversion of RFs using $\mathrm{NA}$, and modelling of variations in RFs with back-azimuth) and we were able to confirm several crustal features of the Lachlan Orogen already identified from previous seismic refraction (Finlayson et al. 2002) and reflection profiles (Direen et al. 2001; Glen et al. 2002). The crust-mantle boundary is deep and mostly intermediate in character in the Lachlan Orogen and could arise 
from underplating at the base of the lower crust and the thick piles of Ordovician mafic rocks present in the mid and lower crust (Glen et al. 2002). Moho depth variations suggest a dipping Moho beneath the Lachlan Orogen. Moreover, numerical modelling of RFs suggests the presence of a dipping Moho and crustal anisotropy with a dipping fast axis beneath CAN (at Mount Stromlo). The cause of crustal anisotropy might be due to a strong N-S structural trend in the eastern Lachlan Orogen, which extends from the surface to Moho with a variable dip (e.g. Foster \& Gray 2000) and possibly to the preferred crystallographic orientation of minerals in the middle and lower crust caused by paleo-Pacific plate convergence, which might also give rise to the dipping Moho and crustal thickening to the west beneath CAN station. This crustal thickening may also be related to the broad Macquarie volcanic arc, which is rooted to the Moho.

However, it is difficult to distinguish between a dipping seismic discontinuity and the effect of crustal anisotropy with a dipping fast axis on RFs. The complexity of the results for a very high-quality permanent station CAN indicates the difficulties we face when we have probes with a limited directional resolution. Where RFs can be combined with other classes of information from, e.g. geological information, surface waves, it may be possible to resolve some of the ambiguities.

We confirm a thickened crust beneath the Lachlan orogeny with complex fabric and rapid changes in crustal properties. The presence of a group of high-quality stations enables us to pick up the dip of the Moho and recognise features that seem to have been induced in the compression associated with the construction of the Orogen, including the presence of crustal anisotropy.

\section{ACKNOWLEDGEMENTS}

We thank M. S. Sambridge for his inversion program, A. Frederiksen \& M. Bostock for the code to compute synthetic seismograms in anisotropic media. We are grateful to Nick Direen for constructive review. We would also like to thank members of the RSES group for help in the fieldwork deployments, and to the landowners for their support. We are grateful to the developers of GMT software (Wessel \& Smith 1991). CAN station is maintained by GEOSCOPE (IPGP) and the Australian National University. CNB and YNG are maintained by Geoscience Australia.

\section{REFERENCES}

BAnNister S., Yu J., Leitner B. \& Kennett B. L. N., 2003. Variations in crustal structure across the transition from West to East Antarctica, Southern Victoria Land. Geophysical Journal International 155, 870-884.

BarRuol G. \& Hoffmann R. 1999. Seismic anisotropy beneath the Geoscope stations from SKS splitting. Journal of Geophysical Research 104, 10757-10774.

BARRUol G. \& Kern H. 1996. Seismic anisotropy and shear-wave splitting in lower-crustal and upper-mantle rocks from the Ivrea Zone-Experimental and calculated data. Physics of the Earth and Planetary Interiors 95, 175-194.

Chevrot S. \& van DER Hilst R. D. 2000. The Poisson ratio of the Australian crust: geological and geophysical implications. Earth and Planetary Science Letters 183, 121-132.
Christensen N. I. 1996. Poisson's ratio and crustal seismology. Journal of Geophysical Research 101, 3139-3156.

Cuitheroe G. M., Gudmundsson O. \& Kennett B. L. N. 2000. The crustal thickness of Australia. Journal of Geophysical Research 105, 13697-13713.

Collins C. D. N., Drummond B. J. \& Nicoll M. G. 2003. Crustal thickness patterns in the Australian continent. Geological Society of Australia Special Publication 22, and Geological Society of America Special Papers 372, 121-128.

ColLins C. D. N. 1991. The nature of the crust-mantle boundary under Australia from seismic evidence. In: Drummond B. J. ed. The Australian lithosphere. Geological Society of Australia Special Publication $17,67-80$.

ColLINS W. J. 2002a. Hot orogens, tectonic switching, and creation of continental crust. Geology 30, 535-538.

CoLLINS W. J. 2002b. Nature of extensional accretionary origins. Tectonics 21, 1024-1036.

CRAMPIN S. 1994. The fracture criticality of crustal rocks. Geophysical Journal International 118, 428-438.

Cull J. P., O’Reilly S. Y. \& GRIFFin W. L. 1991. Xenolith geotherms and crustal models in eastern Australia. Tectonophysics 192, 359-366.

Direen N. G. \& CRAwford A. J. 2003. The Tasman Line: where is it, what is it, is it Australia's Rodinian breakup boundary? Australian Journal of Earth Sciences 50, 491-502.

Direen N. G., Lyons P., Korsch R. J. \& GLen R. A. 2001. Integrated geophysical appraisal of crustal architecture in the Eastern Lachlan Orogen. Exploration Geophysics 32, 252-262.

Drummond B. J. \& Collins C. D. N. 1986. Seismic evidence for underplating of the lower continental crust of Australia. Earth and Planetary Science Letters 79, 361-372.

Farra V., Vinnik L. P., Romanowicz B., Kosarev G. L. \& Kind R. 1991. Inversion of teleseismic $S$ particle motion for azimuthal anisotropy in the upper mantle: a feasibility study. Geophysical Journal International 106, 421-431.

Finlayson D. M., Korsch R. J., Glen R. A., Leven J. H. \& Johnstone D. W. 2002. Seismic imaging and crustal architecture across the lachlan transverse zone, a crosscutting feature of eastern Australia. Australian Journal of Earth Sciences 49, 311-321.

Finlayson D. M., Coluins C. D. N. \& Denham D. 1980. Crustal structure under the Lachlan Fold Belt, southeastern Australia. Physics of the Earth and Planetary Interiors 21, 321-342.

Fontaine F. R., Tkalcic H. \& Kennett B. L. N. 2013. Imaging crustal structure variation across southeastern Australia. Tectonophysics 582, 112-125.

Fontaine F. R., Barruol G., Kennett B. L. N., Bokelmann G. \& Reymond D. 2009. Upper mantle anisotropy beneath Australia and tahiti from $\mathrm{p}$-wave polarisation-implications for real-time earthquake location. Journal of Geophysical Research 114, B03306, doi:10.1029/2008JB005709.

Foster D. A. \& Gray D. R. 2000. Evolution and structure of the Lachlan Fold Belt (Orogen) of Eastern Australia. Annual Reviews of Earth and Planetary Sciences 28, 47-80.

Frederiksen A. W., Folsom H. \& Zandt G. 2003. Neighbourhood inversion of teleseismic ps conversions for anisotropy and layer dip. Geophysical Journal International 155, 200-212.

Frederiksen A. W. \& Bostock M. G. 2000. Modelling teleseismic waves in dipping anisotropic structures. Geophysical Journal International 141, 401-412.

Giese P. 2005. Moho discontinuity. In: Selly R. C., Cocks L. R. M. \& Plimer I. R. eds., Encyclopedia of geology, pp. 645-659. Elsevier Academic Press, Oxford.

Glen R. A., Korsch R. J., Direen N. G., Jones L. E. A., Johnstone D. W., LaWrie K. C., Finlayson D. M. \& ShaW R. D. 2002. Crustal structure of the Ordovician Macquarie Arc, eastern Lachlan Orogen, based on seismic-reflection profiling. Australian Journal of Earth Sciences 49, 323-348.

Gray D. R. \& Foster D. A. 2004. Tectonic evolution of the Lachlan Orogen, southeast Australia: historical review, data synthesis and modern perspectives. Australian Journal of Earth Sciences 51, 773-817.

Haskell N. A. 1953. The dispersion of surface waves in multilayered media. Bulletin of the Seismological Society America 43, 17-34.

Heintz M. \& KenNetr B. L. N. 2005. Continental scale shear wave splitting analysis: Investigation of seismic anisotropy underneath the Australian continent. Earth and Planetary Science Letters 236, 106-119. 
Kennett B. L. N., Salmon M., Saygin E. \& AusMoho Group 2011. AusMoho: the variation of Moho depth in Australia. Geophysical Journal International 187, 946-958.

KeRn H. \& Wenk H-R. 1990. Fabric-related velocity anisotropy and shear wave splitting in rocks from the Santa Rosa Mylonite Zone. Journal of Geophysical Research 95, 11213-11223.

Langston C. A. 1977. Corvallis, Oregon, crustal and upper mantle structure from teleseismic body waves. Bulletin of the Seismological Society America 67, 713-724.

Langston C. A. 1979. Structure under Mount Rainier, Washington, inferred from teleseismic body waves. Journal of Geophysical Research 84, 4749-4762.

McDonough W. F., Rudnick R. L. \& McCulloch M. T. 1991. The chemical and isotopic composition of the lower eastern Australian lithosphere: a review. In: Drummond B. J. ed. The Australian Lithosphere, pp. 163-188. Geological Society of Australia Special Publication 17.

O’Reilly S. Y. 1989. Nature of the Australian lithosphere. In: Johnson R. W. ed. Intraplate volcanism in Eastern Australia and New Zealand, pp. 290-297. Cambridge University Press, Cambridge.

Peng X. \& Humphreys E. D. 1997. Moho Dip and Crustal Anisotropy in Northwestern Nevada from Teleseismic Receiver Functions. Bulletin of the Seismological Society of America 87, 745-754.

Rawlinson N., Kennett B. L. N., Vanacore E., Glen R. A. \& Fishwick S. 2010. The structure of the upper mantle beneath the Delamerian and Lachlan orogens from simultaneous inversion of multiple teleseismic datasets. Gondwana Research 19, 788-799.

SAMBRIDGE M. S. 1999. Geophysical inversion with a neighbourhood algorithm. I. Searching a parameter space. Geophysical Journal International 138, 479-494.

SAVAGE M. K. 1998. Lower crustal anisotropy or dipping boundaries? Effects on receiver functions and a case study in New Zealand. Journal of Geophysical Research 103, 15 069-15 087.

SAYGIN E. 2007. Seismic receiver and noise correlation based studies in Australia. PhD thesis, The Australian National University, Canberra.
Schulte-Pelkum V., Masters G. \& Shearer P. M. 2001. Upper mantle an isotropy from long-period P polarization. Journal of Geophysical Research 106, 21 917-21 934.

Sherrington H. F., Zandt G. \& Frederiksen A. 2004. Crustal fabric in the Tibetan Plateau based on waveform inversions for seismic anisotropy parameters. Journal of Geophysical Research 109, B02312, doi:10.1029/2002JB002345.

Shibutani T., SAmbridge M. S. \& Kennett B. L. N. 1996. Genetic algorithm inversion for receiver functions with application to crust and uppermost mantle structure beneath Eastern Australia. Geophysics Research Letters 23, 1826-1832.

Siegesmund S., Takeshita T. \& Kern H. 1989. Anisotropy of Vp and Vs in an amphibolite of the deeper crust and its relationship to the mineralogical, microstructural, and textural characteristics of the rock. Tectonophysics 157, 25-38.

Thоmson W. T. 1950. Transmission of elastic waves through a strati fied solid. Journal of Applied Physics 21, 89-93.

Tkalčić H., Chen Y., Liu R., Huang H., Sun L. \& Chan W. 2011. Multi-step modelling of teleseismic receiver functions combined with constraints from seismic tomography: Crustal structure beneath southeast China. Geophysical Journal International 187, 303-326.

VinNIK L. P., FARRA V. \& Romanowicz B. 1989. Azimuthal anisotropy in the Earth from observations of SKS at Geoscope and NARS broadband stations. Bulletin of the Seismological Society of America 79, 1542-1558.

Weiss T., Siegesmund S., Rabbel W., Bohlen T. \& Pohl M. 1999. Seismic velocities and anisotropy of the lower continental crust: A review. Pure App. Geophys. 156, 97-122.

Wessel P. \& Smith W. H. 1991. Free software helps map and display data. Eos Transactions, AGU 72, 441-446.

ZHU L. \& KANAMORI H. 2000. Moho depth variation in southern California from teleseismic receiver functions. Journal of Geophysical Research 105, 2969-2980.

Received 10 July 2012; accepted 12 March 2013

\section{SUPPLEMENTARY PAPERS}

Details of H-K stacking method

Nonlinear waveform inversion for RF

Analysis for anisotropy and dipping layers

$\mathrm{P}$-wave polarisation 